\title{
Amphiphilic zwitterionic-PDMS-based surface-modifying additives to tune fouling-release of siloxane-polyurethane marine coatings
}

\author{
AliReza Rahimi, ${ }^{a}$ Shane J. Stafslien, ${ }^{a}$ Lyndsi Vanderwal, ${ }^{a}$ John A. Finlay, ${ }^{b}$ Anthony S. Clare, ${ }^{b}$ Dean C. \\ Webster $^{\mathrm{a}^{*}}$ \\ ${ }^{a}$ Department of Coatings and Polymeric Materials, North Dakota State University, Fargo, ND 58108, \\ USA \\ ${ }^{\mathrm{b}}$ School of Natural and Environmental Sciences, Newcastle University, Newcastle upon Tyne, NE1 \\ 7RU, UK
}

*Corresponding author: Email: dean.webster@ndsu.edu

\section{Abstract}

Amphiphilic coatings have shown promising performance for marine applications to deter and limit biofouling. Hydrophobic marine coatings are unable to deter marine organisms that prefer hydrophobic surfaces for settlements, thus a series of amphiphilic additives were prepared and introduced to a hydrophobic system to attain surface amphiphilicity and improved performance without changing the base matrix. In this work, we report the successful synthesis of amphiphilic additives where highly incompatible blocks of hydrophobic polydimethylsiloxane (PDMS) and hydrophilic poly(sulfobetaine methacrylate) (poly(SBMA)) were connected, using ARGET ATRP (activators regenerated by electron transfer atom transfer radical polymerization) controlled radical polymerization technique. The surface characterization confirmed the presence of self-migrated amphiphilic additives to the surface of hydrophobic coating systems, and biological assessments indicated that the additives desirably improved fouling-release performance of the base hydrophobic system against macroalgal spores (Ulva linza) and barnacles (Amphibalanus amphitrite) while these additives had no detrimental effect on ability of the base matrix to release bacteria (Cellulophaga lytica), diatoms (Navicula incerta), and mussels (Geukensia demissa). Furthermore, this study not only reported the outstanding contribution of poly(SBMA)-PDMS additives towards contending with marine biofouling as well as the facile preparation of amphiphilic additives, but also concluded that several factors should be considered in the design of these additives for tailoring hydrophobic coatings: 1) PDMS block with a molecular weight of $1000 \bar{M}_{n}$ is preferred over higher molecular weights of PDMS; 2) hydrophilic portion between a range of $50 \%$ to $80 \%$ provides the desired 
amphiphilicity on a surface; and 3) poly(SBMA) block size does not necessarily impact the effectiveness of an additive.

Keywords: Amphiphilic; siloxane-polyurethane; marine coating; fouling-release; self-stratification; zwitterionic

\section{Introduction}

Marine biofouling is the undesirable accumulation of marine micro- and macro-organisms on submerged structures in seawater. ${ }^{1}$ Biofouling imposes a complex problem that not only causes unappealing aesthetic effects, but it also has penalized the marine industry for centuries through significant economic and environmental drawbacks. The estimates report that biofouling costs $\$ 1$ billion per year to the United States Navy alone. ${ }^{2}$ The continuous settlement of marine organisms on ships' hulls creates frictional drag, which eventually leads to reduced speed and maneuverability, resulting in increased fuel consumption and gaseous emissions. ${ }^{3}$ Estimates have shown that even a $2 \%$ reduction in ship speed can drop fuel efficiency significantly. ${ }^{4} \mathrm{~A}$ biofouled ship, therefore, should undergo frequent dry-docking, enforcing severe economic penalties on ship owners. Additionally, given the global nature of shipping routes, biofouling also threatens natural environments through transportation of invasive species. ${ }^{2}$

The process of marine biofouling is a complex phenomenon of multiple stages that worldwide involves more than 4000 marine organisms with varying sizes, surface type affinities, and mechanisms of adhesion. The process starts immediately when a structure is immersed in seawater proteins, nutrients, and other small molecules settle on the surface and form a conditioning film. This is followed by marine bacteria as well as slime forming algae (diatoms), which colonize within minutes and form a biofilm. Alongside the microorganisms, macro-organisms such as barnacles and mussels will settle on the surface too but at a slower rate. While marine biofouling is often viewed as a linear chain of fouling events, from micro- to macro-organisms, this is not necessarily the case and macro- 
foulants, such as the barnacle $A$. amphitrite and the green alga $U$. linza are known to adhere to clean or newly immersed surfaces without the presence of microbial films ${ }^{1,3}$

Historically, the protection of ships' hulls has taken many forms, with copper alloys and lead sheathing giving way to biocide-containing antifouling paints by the $1900 \mathrm{~s} .{ }^{5}$ The effectiveness of these peaked with the introduction of tributyl tin-based self-polishing copolymer coatings in the 1970s. However, the paints were toxic to non-targeted marine species, ${ }^{6}$ resulting in a worldwide ban of organotin-based coatings by the International Marine Organization (IMO) due to their harmful effects to aquatic ecosystems. ${ }^{3,7}$ Therefore, to address regulations, the focus of many recent studies has been to develop antifouling (AF) coatings and fouling-release (FR) coatings that are non-toxic.

The most common antifouling coatings used today contain copper oxide-based components, which although less toxic than organotin materials, release metal ions into aquatic environments with potential negative impact on marine ecosystems. FR systems offer a completely non-toxic and ecofriendly approach to combat biofouling. FR coatings do not release any chemicals, rather they prevent strong adhesion of marine organisms to the surface of structures, which facilitates easy removal of the foulants when subjected to hydrodynamic pressure upon movement of ships or light cleaning. ${ }^{1,3}$ As a result, FR systems have remained of special interest to avoid application of biocidecontaining paints.

Traditional FR systems are mainly made of elastomeric materials such as polydimethylsiloxane (PDMS), fluoropolymers, or other silicones. ${ }^{3}$ Additionally, PDMS and materials similar to it, possess low surface energy, which acts as a driving force for weak adhesion of organisms, introducing the fouling release mechanism upon exposure of settled foulants to hydrodynamic pressure. ${ }^{3}$ Nevertheless, commercial coatings made of these low surface energy components suffer from poor mechanical durability and require a tie-coat to achieve proper adhesion to a substrate..$^{3,5}$ To address the durability and tie-coat limitations while ensuring desirable FR performance is met, hydrophobic siloxane-polyurethane (SiPU) FR coatings have been developed that display FR performance comparable to or better than commercially available products with strong 
adhesion to a substrate and a magnitude higher bulk modulus. The SiPU coatings benefit from the combination of two incompatible materials: polyurethane (PU), which is polar with high surface energy, and PDMS, which is non-polar with low surface energy. The incompatibility causes selfstratification of components with PDMS segregating to the surface, tackling the biofouling issue, while the PU remains in contact with the substrate offering good mechanical strength and strong adhesion. ${ }^{8-}$ 10

Although hydrophobic FR systems, like SiPU, can combat some biofouling species effectively, there are still marine organisms that can settle and adhere firmly on such surfaces. The difference in adherence of foulants to FR coating surfaces is not surprising given the wide variety of marine fouling organisms with differing surface affinities, from hydrophilic to hydrophobic surfaces, and adhesion mechanisms. ${ }^{7}$ For example, U. linza, mussels, and barnacles attach strongly to hydrophilic surfaces, while the diatom, $N$. incerta, attaches strongly to hydrophobic surfaces and the marine bacterium, $C$. lytica, settles on a variety of surfaces. Therefore, amphiphilic surfaces that contain both hydrophobic and hydrophilic domains have been investigated for their potential to tackle biofouling against a wider range of biofoulants.

Amphiphilic systems take advantage of the protein-resistant characteristics of hydrophilic materials that deter biofouling. ${ }^{11}$ Polyethylene glycol (PEG) is one of the commonly investigated materials as it resists protein absorption and possesses non-toxic and nonimmunogenic properties. PEG-modified surfaces interfere with protein binding through hydrophilic interactions of the surface with water. ${ }^{12-14}$ Self-assembled monolayers (SAM) containing PEG are commonly explored as proteinresistant materials for biomedical applications, ${ }^{15}$ but the application of SAMs as marine coatings is not feasible. As a viable approach, PEG-modified amphiphilic siloxane-polyurethane coatings were designed to benefit from properties of PEG, which resulted in broadened performance against marine organisms. ${ }^{16}$ However, PEG experiences rapid autoxidation in the presence of transition metals in both the biological and marine environments, appearing as a less suitable candidate for long-term use in marine coatings. ${ }^{17}$ Alternatively, zwitterionic materials are recognized as another major category of 
hydrophilic, protein-resistant and ultra-low fouling materials that can bind water molecules even more strongly and offer prolonged stability, ${ }^{18,19}$ where phosphobetaine, sulfobetaine, and carboxybetaine are examples of zwitterionic candidates. ${ }^{20-24}$ Considering the promise of zwitterionic materials, several amphiphilic coating systems have been explored that entail crosslinking of these hydrophilic materials in networks..$^{22,25-27}$

Even though innovating a new amphiphilic coating system is enticing, it is often preferred and more feasible to utilize surface-modifying additives that do not necessitate substantial changes for an established FR formulation. The additives for marine purposes are mostly prepared as surfacemodifying agents to adjust the surface of coatings and boost their performance as FR or AF coatings. Several additives have been examined for marine coatings including copper/zinc-based, ${ }^{28-30}$ amphiphilic copolymers (i.e. $\mathrm{PEG}^{31-37}$ or zwitterionic-based ${ }^{38-42}$ ), or hydrogel-like polymers. ${ }^{43}$ Additionally, silicone oils ${ }^{44-46}$ and specialty additives such as sephiolite nanofibers, modified graphite, carbon nanotubes and pigments (i.e. $\mathrm{TiO}_{2}$ and $\left.\mathrm{ZnO}\right)^{47-51}$ have been used to boost performance of marine coatings. While amphiphilic copolymers are widely desired as surface-active additives, their preparation usually involves complex synthesis procedures which limits their scale-up beyond academia.

Therefore, this study aimed to prepare a series of amphiphilic surface-modifying additives using a facile synthetic procedure and evaluate their effect on tailoring the fouling-release performance of a control hydrophobic SiPU coating system. This work reports the successful and sustainable synthesis of amphiphilic additives where highly incompatible polymeric blocks of hydrophobic polydimethylsiloxane (PDMS) and hydrophilic poly(sulfobetaine methacrylate) (poly(SBMA)) were connected, using ARGET ATRP (activators regenerated by electron transfer atom transfer radical polymerization) controlled polymerization technique. To synthesize amphiphilic additives, ATRP macroinitiators based on polydimethylsiloxane (PDMS) were prepared, and hydrophilic chains of zwitterionic poly(SBMA) were grown from them. Moreover, the ARGET ATRP method was used over other conventional ATRP techniques, providing benefits of eliminating the 
need for a glovebox, utilizing vitamin $\mathrm{C}$ (ascorbic acid) as a reducing agent, and lowering the amount of required copper catalyst to $<300 \mathrm{ppm}$. As these amphiphilic additives are designed to be introduced non-covalently to a base hydrophobic matrix, the PDMS segment facilitates their self-stratification to the coating/air interface as a result of its low surface energy as well as its incompatibility with the coating composition. ${ }^{8,9}$ In water, poly(SBMA) zwitterionic segment of the additive will form a highly hydrated aqueous structure (up to 8 times more than PEG) at the surface. ${ }^{23,24}$ The hydrated layer will not be readily displaced by marine organisms, limiting their ability to settle and adhere on the surface of a coating. In addition to high water absorbance of poly(SBMA), it was selected over PEG for its long-term stability and ultra-low fouling properties. Thus, a combination of both PDMS and poly(SBMA) will potentially form a coating surface that has both hydrophobic and hydrophilic characteristics, respectively, to combat settlement of a wider range of organisms.

\section{Experimental}

\section{Materials}

Desmodur Z4470 BA (isophorone diisocyanate-based polyisocyanate (IPDI)) was provided by Covestro LLC. All monofunctional carbinol-terminated polydimethylsiloxane (CT-PDMS) and difunctional CT-PDMS were purchased from Gelest Inc, where monofunctional CT-PDMS were designated as DMS-C15 $\left(1 \mathrm{k} \bar{M}_{n}\right)$, DMS-C21 $\left(5 \mathrm{k} \bar{M}_{n}\right)$ and DMS-C23 $\left(10 \mathrm{k} \bar{M}_{n}\right)$ and difunctional CTPDMS were cataloged as MCR-C12 $\left(1 \mathrm{k} \bar{M}_{n}\right)$, MCR-C18 $\left(5 \mathrm{k} \bar{M}_{n}\right)$ and MCR-C22 (10k $\left.\bar{M}_{n}\right)$. Copper (II) chloride, 2-(dimethylamino) ethyl methacrylate, 1-3-propane sultone, ascorbic acid (vitamin C), 2,2'bipyridine, a-bromoisobutyryl bromide (BIBB), triethylamine, dibutyltin diacetate (DBTDAc), deuterated dimethyl sulfoxide (DMSO), tetrahydrofuran (THF), toluene, chloroform, acetone, acetylacetone, and methyl amyl ketone (MAK), drying molecular sieves of $4 \AA$ size were purchased from Sigma-Aldrich. A solution of DBTDAc was prepared by mixing $1 \%$ by wt. in MAK. An acrylic polyol composed of $80 \%$ butyl acrylate and 20\% 2-hydroxyethyl acrylate was synthesized via conventional free radical polymerization and diluted to $50 \%$ with toluene. Aminopropyl-terminated polydimethylsiloxane (APTPDMS) with molecular weight (MW) of 20,000 $\bar{M}_{n}$ was also synthesized through a ring-opening 
equilibration reaction. Detailed descriptions of synthesis procedures for both the acrylic polyol and APT-PDMS can be found elsewhere. ${ }^{9}$

AkzoNobel, International Paint Ltd. provided the commercial FR standards Intersleek® 700 (IS 700), Intersleek® 900 (IS 900), and Intersleek® 1100SR (IS 1100). The silicone elastomer, Silastic® T2 (T2), and control thermoplastic polystyrene (PS) was provided by Dow Corning. Aluminum panels (4" x 8" in., $0.6 \mathrm{~mm}$ thick, type A, alloy $3003 \mathrm{H14}$ ) and steel panels were purchased from Q-lab; the aluminum panels were sandblasted and primed with Intergard 264 (International Paint) using airassisted spray application. Multi-well plates were modified using circular disks (1-inch diameter) of primed aluminum. ${ }^{52}$

\section{Synthesis of sulfobetaine methacrylate (SBMA) monomer}

The synthesis of SBMA monomer was carried out following a procedure elsewhere as a closed system. ${ }^{53}$ Briefly, in a $250-\mathrm{mL}$ one-neck round-bottom flask equipped with a magnetic stirrer and a thermocouple, 2-(dimethylamino) ethyl methacrylate (30.0 g; 0.19 mole) and acetone $(90.0 \mathrm{~mL})$ were charged, and the contents were stirred at $30^{\circ} \mathrm{C}$. A solution of 1,3-propane sultone (23.3 g; 0.19 mole) and acetone $(10 \mathrm{~mL})$ was added dropwise, over 30 minutes, to the flask. After the addition of the solution, the reaction was stirred at $30^{\circ} \mathrm{C}$ for four hours and then allowed to stand at room temperature for one week. No reflux condenser was used as the reaction temperature was much lower than the boiling point of acetone and any evaporated acetone would condense back after contacting the glass surface on top of the flask. The monomer precipitated out as white crystals and was collected by filtration, washed with dry acetone three times, and dried under vacuum overnight to obtain sulfobetaine methacrylate (Scheme 1). The product was confirmed by proton nuclear magnetic resonance $\left({ }^{1} \mathrm{H}-\mathrm{NMR}\right)$ and Fourier transform infrared spectroscopy (FTIR).

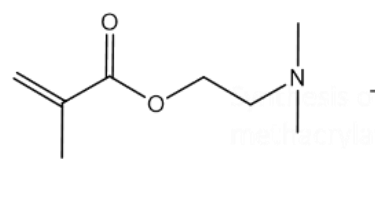

2-(dimethylamino) ethyl methacrylate

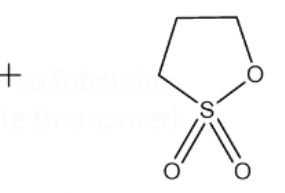

1,3 - Propane sultone
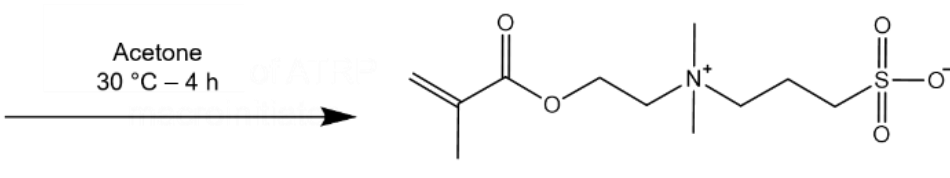

Sulfobetaine methacrylate 


\section{Scheme 1. Synthesis of SBMA monomer}

Synthesis of ARGET-ATRP macroinitiator (Br-terminated PDMS)

The reaction to synthesize the macroinitiator is shown in Scheme 2. The mole ratio of CTPDMS: triethylamine: BIBB was 1.00:1.00:1.16 and 1.00:2.00:2.30 for mono-functional CT-PDMS and di-functional CT-PDMS, respectively. In a 500-mL three-neck round-bottom flask equipped with an addition funnel, magnetic stirrer, and thermocouple, CT-PDMS and triethylamine were dissolved in $200 \mathrm{~mL}$ dry THF solvent. The flask was placed in an ice bath and the contents were stirred at $0-5^{\circ} \mathrm{C}$. A solution of BIBB and $10 \mathrm{~mL}$ THF was added dropwise to the flask while maintaining the temperature at $0-5^{\circ} \mathrm{C}$. After the addition of the solution, the reaction was stirred at room temperature overnight. Next, the generated white precipitate was removed using a fritted funnel, and solvent was removed under vacuum. Then, $100 \mathrm{~mL}$ of dichloromethane was added to the condensed contents, and they were washed with water 3 times (100 mL each time). The organic layer was collected, dried over $\mathrm{MgSO}_{4}$, filtered, condensed in a rotary evaporator, and dried in vacuo overnight. The synthesized macroinitiator was characterized by ${ }^{1} \mathrm{H}-\mathrm{NMR}$ and FTIR. ${ }^{54}$

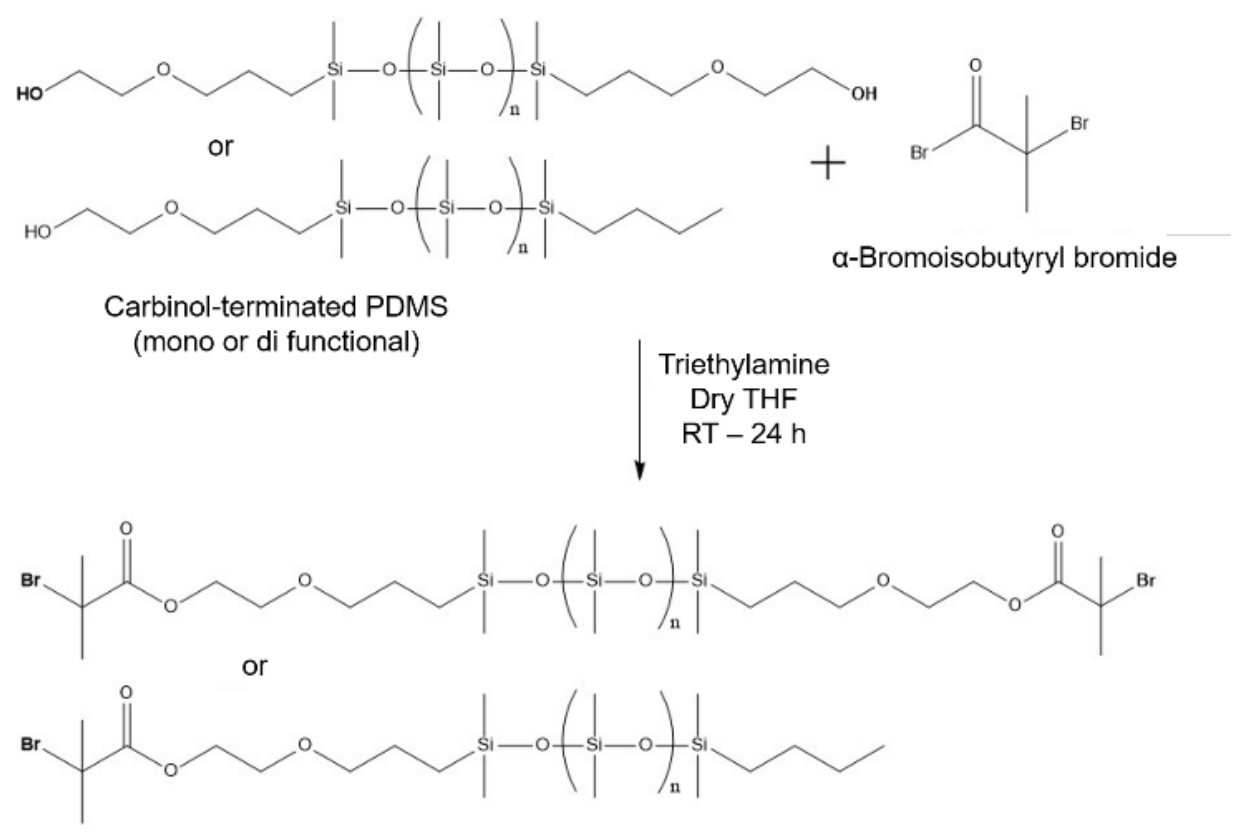

Scheme 2. Synthesis of Br-PDMS macroinitiator for ARGET-ATRP polymerization technique Synthesis of amphiphilic additives 
Amphiphilic additives that contained zwitterionic poly(SBMA) block(s) and PDMS block were synthesized through the ARGET-ATRP technique, which provided the advantage to control chain length of poly(SBMA) attached to the PDMS block. ${ }^{54-56}$ This polymerization technique allows synthesis of polymers with targeted chain lengths, requires negligible catalyst content (ppm concentration) and utilizes vitamin C (ascorbic acid) as a reducing agent. Also, there is no need for a glove box to run this polymerization since the catalyst precursor is more stable for ARGET ATRP than conventional ATRP. ARGET ATRP requires solvent plus five components including monomer, macroinitiator, catalyst, reducing agent, and a ligand: sulfobetaine methacrylate (SBMA), Br-terminated PDMS, $\mathrm{Cu}$ (II) $\mathrm{Cl}$, vitamin C (ascorbic acid), and 2,2'-bipyridine, respectively.

The ratio of $[\mathrm{SBMA}]_{0} /[\mathrm{Br}-\mathrm{PDMS}-\mathrm{Br}]_{0} /\left[\mathrm{CuCl}_{2}\right]_{0} /[\mathrm{bpy}]_{0} /[\mathrm{Vitamin} \mathrm{C}]_{0}$ for the polymerization was 100/0.2/0.01/0.05/0.15. For example, to synthesize $10 \mathrm{~g}$ of triblock additive 2500-1000-2500 (where 2500 is $\bar{M}_{n}$ molecular weight of each poly(SBMA) chain attached on a di-functional $1000 \bar{M}_{n}$ CTPDMS), the mentioned reagents were added in 10,000 mg/ $2596 \mathrm{mg} / 13 \mathrm{mg} / 78 \mathrm{mg} / 264 \mathrm{mg}$. The reaction is illustrated in Scheme 3. In a 100-mL one-neck round-bottom flask equipped with a magnetic stirrer, Br-PDMS macroinitiator and $40 \mathrm{~mL}$ methanol was charged and stirred at room temperature. A solution of SBMA monomer dissolved in $5 \mathrm{~mL}$ methanol was added to the flask. The contents were stirred for 5 minutes to obtain a homogenous mixture. A solution of 2,2'-bipyridine and $\mathrm{Cu}$ (II) $\mathrm{Cl}$ in $5 \mathrm{~mL}$ methanol was added to the flask. The flask was sealed, and a flow of nitrogen gas was injected into the flask for 30 seconds. A solution of ascorbic acid in $2 \mathrm{~mL}$ water was injected into the flask using a syringe to initiate the polymerization reaction. The reaction was stirred at room temperature for 48 hours. After this time, the polymer was precipitated in methanol. The solvent was removed by a rotary evaporator. Then, as the amphiphilic product was not soluble in water or common organic solvents, the contents were washed with both water and dichloromethane 3 times (50 $\mathrm{mL}$ each time). The remaining residual solvent was removed using a rotary evaporator and the product was dried in vacuo at $40^{\circ} \mathrm{C}$ overnight. The synthesized macroinitiator was characterized by ${ }^{1} \mathrm{H}-\mathrm{NMR}$ and FTIR. GPC could not be run on these block copolymers also due to their insolubility 
limitations in common solvents like THF or water; however, ARGET-ATRP polymerization was conducted using the same procedure with butyl methacrylate and Br-PDMS and GPC confirmed a triblock copolymer of targeted $6000 \bar{M}_{n}$ (PDI 1.12). A control poly (SBMA) additive (with no PDMS in its backbone) was also synthesized using the same procedure using BIBB initiator.

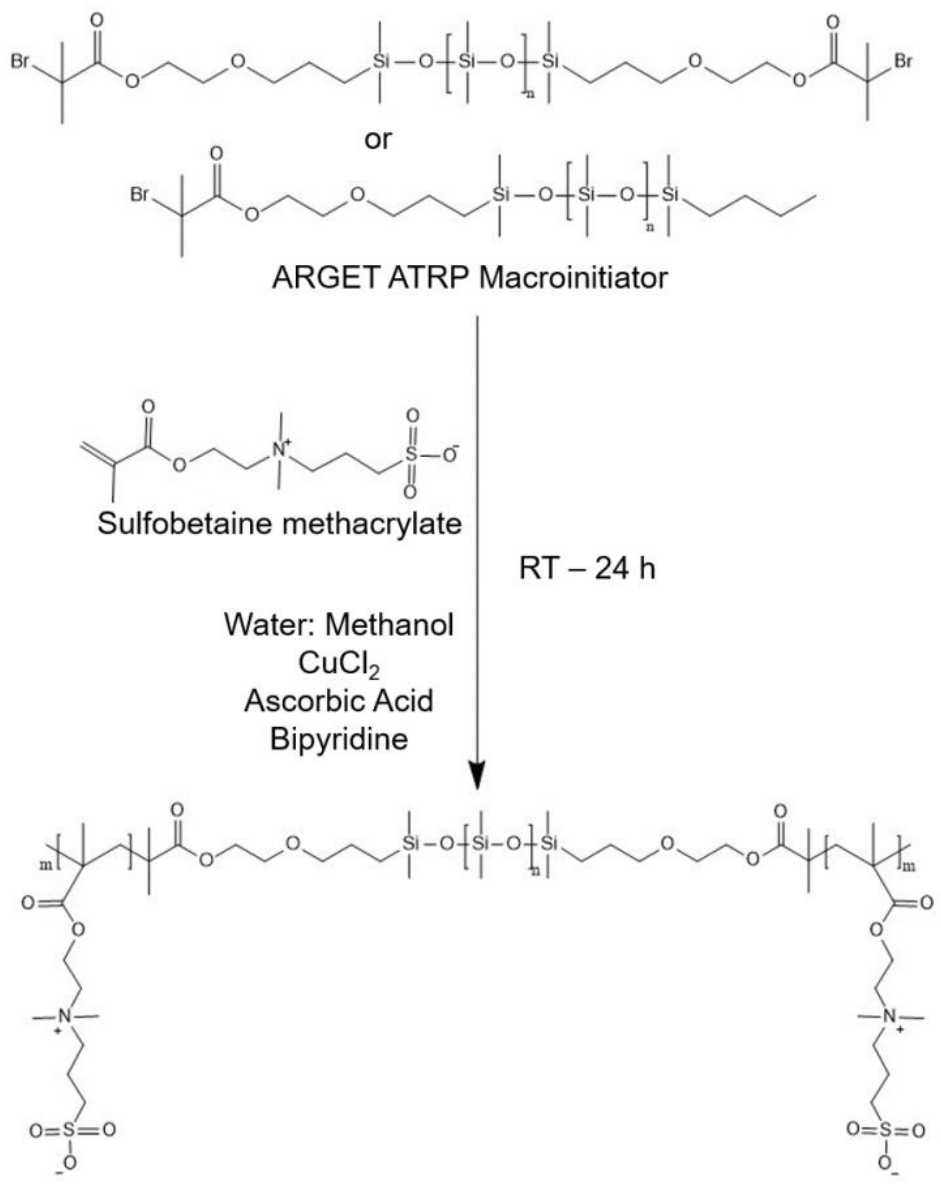

Scheme 3. Synthesis of amphiphilic copolymeric additive via ARGET ATRP polymerization method

\section{$\underline{\text { Coating Formulations }}$}

All synthesized additives in this study were added to the SiPU A4-20 formulation to tune its marine performance. The A4-20 formulation consists of an IPDI trimer isocyanate resin that is crosslinked with an acrylic polyol and an amine-terminated PDMS, being an inherently hydrophobic fouling-release coating. An amphiphilic additive was the only variable that was added to SiPU A4-20 system for a studied formulation. Additives were added in wt. \% of total solid content of the A4-20 
system. For example, to formulate a formulation with $1 \mathrm{wt} \%$ of additive, acrylic polyol $(16.71 \mathrm{~g})$ and additive $(0.17 \mathrm{~g})$ were added in a vial, sonicated for 15 minutes and magnetically stirred at ambient condition for 24 hours. APT-PDMS $(3.34 \mathrm{~g})$ and acetylacetone $(1.65 \mathrm{~g})$ were added to the vial. The mixture was sonicated for 15 minutes and was magnetically stirred at ambient condition for another 24 hours. IPDI trimer Desmodur Z4470 BA resin $(7.41 \mathrm{~g})$ and DBTDAc catalyst solution $(0.66 \mathrm{~g})$ were added to the vial, and the mixture was stirred for another hour. After mixing, coating formulations were deposited into multi-well plates using an automatic repeat pipette $(250 \mu \mathrm{L}$ of formulation was deposited into each well in multi-well plate). Drawdowns were made on primed 8' x 4' aluminum panels using a wire-wound drawdown bar with a wet film thickness of $80 \mu \mathrm{m}$. All coatings were cured under ambient conditions for 24 hours followed by oven curing at $80^{\circ} \mathrm{C}$ for $45 \mathrm{~min}$.

\section{Experimental Design}

This study was designed to assess 12 additives (Table 1). Additives are labeled based on the MW of their polymeric blocks, where the first and third number (applicable for triblock additives) is always MW of poly(SBMA) chain(s) and the second number is MW of PDMS.

Four variables were evaluated to establish an understanding and correlation between a designed additive and fouling-release performance. The variables were PDMS average molecular weight $\left(1,000 \bar{M}_{n}, 5,000 \bar{M}_{n}, 10,000 \bar{M}_{n}\right)$, poly(SBMA) molecular weight $\left(500 \bar{M}_{n}, 1,000 \bar{M}_{n}, 2,500\right.$ $\bar{M}_{n}$ ), additive type (di-blocks vs tri-blocks) and addition amount to a coating $(0.2,1,5$, and 10 wt. \% in relation to non-volatile coating ingredients). A total of 43 coatings were formulated (Table S1, Supporting Information). Formulations are labeled based on the type and amount of incorporated additive. For example, formulation " $500-1 \mathrm{k} 1 \%$ " refers to an additive with $500 \bar{M}_{n}$ poly(SBMA) block and $1,000 \bar{M}_{n}$ PDMS block that is added in 1 wt. \% to A4-20 coating system. Eight formulations were shortlisted and discussed in this paper (Table 2) after preliminary fouling-release assessments against $C$. lytica (Figure S1) and $U$. linza (Figure S2), and these eight were further investigated against $U$. linza, barnacles, and mussels. Table 2 also outlines the percentage of hydrophilic portion 
for an additive, which is calculated by dividing the MW of hydrophilic block(s) by the total molecular weight of an additive and then multiplying by 100 .

Table 1. Synthesized copolymeric additives

\begin{tabular}{|c|c|c|c|}
\hline Additive ID & $\begin{array}{l}\text { Additive } \\
\text { Type }\end{array}$ & $\begin{array}{l}\text { MW of a poly(SBMA) Block } \\
\qquad\left(\bar{M}_{n}\right)\end{array}$ & MW of PDMS Block $\left(\bar{M}_{n}\right)$ \\
\hline $500-1 \mathrm{k}$ & \multirow{3}{*}{ Di-block } & 500 & 1000 \\
\hline $1 \mathrm{k}-1 \mathrm{k}$ & & 1000 & 1000 \\
\hline $2.5 \mathrm{k}-1 \mathrm{k}$ & & 2500 & 1000 \\
\hline $500-1 k-500$ & \multirow{9}{*}{ Tri-block } & 500 & 1000 \\
\hline $1 \mathrm{k}-1 \mathrm{k}-1 \mathrm{k}$ & & 1000 & 1000 \\
\hline $2.5 \mathrm{k}-1 \mathrm{k}-2.5 \mathrm{k}$ & & 2500 & 1000 \\
\hline $500-5 k-500$ & & 500 & 5000 \\
\hline $1 k-5 k-1 k$ & & 1000 & 5000 \\
\hline $2.5 \mathrm{k}-5 \mathrm{k}-2.5 \mathrm{k}$ & & 2500 & 5000 \\
\hline $500-10 k-500$ & & 500 & 10000 \\
\hline $1 \mathrm{k}-10 \mathrm{k}-1 \mathrm{k}$ & & 1000 & 10000 \\
\hline $2.5 \mathrm{k}-10 \mathrm{k}-2.5 \mathrm{k}$ & & 2500 & 10000 \\
\hline
\end{tabular}

Table 2. Selected Formulations

\begin{tabular}{|c|c|c|}
\hline Formulation ID & $\begin{array}{c}\text { Incorporated } \\
\text { Additive \& } \\
\text { Percent Amount }\end{array}$ & $\begin{array}{c}\text { Hydrophilic Content \% of Used } \\
\text { Additive }\end{array}$ \\
\hline 3 & $500-1 \mathrm{k} \mathrm{1 \%}$ & 33.3 \\
\hline 6 & $1 \mathrm{k}-1 \mathrm{k} \mathrm{1 \%}$ & 50.0 \\
\hline 9 & $2.5 \mathrm{k}-1 \mathrm{k} \mathrm{1 \%}$ & 71.4 \\
\hline 15 & $1 \mathrm{k}-1 \mathrm{k}-1 \mathrm{k} 1 \%$ & 66.6 \\
\hline 18 & $2.5 \mathrm{k}-1 \mathrm{k}-2.5 \mathrm{k} 1 \%$ & 83.3 \\
\hline 26 & $2.5 \mathrm{k}-5 \mathrm{k}-2.5 \mathrm{k} 1 \%$ & 50.0 \\
\hline 35 & $2.5 \mathrm{k}-10 \mathrm{k}-2.5 \mathrm{k} 1 \%$ & 33.3 \\
\hline 42 & polySBMA 1\% & 100.0 \\
\hline
\end{tabular}

Control and Standard Coatings 
Commercial standards were prepared following manufacturer's specifications. Control SiPU A4-20 was prepared following the procedure outlined in a previous study. ${ }^{9}$ Similar to experimental coatings all control and standards were also prepared on 4" x 8" primed aluminum panels and multi-well plates. Table 3 contains detailed descriptions of the control and standard coatings used for this study.

Table 3. List of control and standard coatings

\begin{tabular}{|c|c|l|}
\hline Control Name & Control ID & \multicolumn{1}{|c|}{ Description } \\
\hline A4-20\% & 1 & Internal Si-PU FR Control \\
\hline NDSU-PU & PU & Pure Polyurethane Standard \\
\hline Dow T2 & T2 & Silicone Elastomer Standard \\
\hline Intersleek® 700 & IS 700 & Commercial FR Standard \\
\hline Intersleek® 900 & IS 900 & Commercial FR Standard \\
\hline Intersleek $® 100 S R$ & IS 1100 & Commercial FR Standard \\
\hline
\end{tabular}

\section{Fourier Transform Infrared Spectroscopy}

Fourier transform infrared (FTIR) spectroscopy was utilized to characterize the monomer, macroinitiators and block copolymers, using a Thermo Scientific Nicolet 8700 FTIR. The liquid resin or prepolymer was spread as a thin layer on a potassium bromide $(\mathrm{KBr})$ plate to collect the spectrum. ${ }^{1} \mathrm{H}-\mathrm{NMR}$

${ }^{1} \mathrm{H}-\mathrm{NMR}$ spectra for a synthesized additive were collected using a Bruker Avance $400 \mathrm{MHz}$ instrument and processed with Topspin software. Peak shifts were calibrated based on residual solvent peaks. Additive samples for NMR experiment were dissolved in deuterated DMSO solvent.

\section{Melting Temperature}

Melting temperature of synthesized SBMA monomer was determined using a Mel-Temp® apparatus equipped with a digital thermometer. The white SBMA powder was introduced into a small capillary tube for measurements.

\section{Surface Characterization}

All experimental coatings were characterized using a Symyx®/First Ten Angstroms system to measure the contact angles and surface energy of the coatings before and after water immersion. 
Water contact angles (WCA) and diiodomethane contact angles (MICA) for each coating were

obtained at $0,3,6,9,15$-minute time intervals to assess changes to measured values over time.

Three measurements of contact angles were obtained using First Ten Angstroms ${ }^{\mathrm{TM}}$ software. Surface energy for each formulation was calculated using the Owens-Wendt method. ${ }^{57}$ Three replicates were recorded for each sample at the above-mentioned time intervals.

Atomic force microscopy (AFM) offered insights into the surface topography of the studied coatings. A Dimension 3100 microscope with Nanoscope controller scanned the surface of experimental coatings, collecting images on a sample area of $100 \mu \mathrm{m} \times 100 \mu \mathrm{m}$ in tapping mode. The experiment was done in air under ambient conditions, using a silicon probe with a spring constant of 0.1-0.6 N/m and 15-39 $\mathrm{kHz}$ resonance frequency.

Attenuated total reflectance-Fourier transform infrared spectroscopy (ATR-FTIR) was used to characterize the surfaces of the coatings. A Bruker Vertex 70 with Harrick's ATR ${ }^{\mathrm{TM}}$ accessory using a hemispherical Ge crystal was used to collect ATR-FTIR spectra for a coating.

\section{Water Aging}

All the prepared coatings were pre-leached for 28 days in running tap water. The water tanks were equipped to automatically fill and empty every 4 hours. Water aging of the coatings was carried out to meet two objectives: 1) to leach out any impurities that might interfere with fouling-release assessments; 2) to determine if there was any significant surface rearrangement of the coatings, or whether the additives leach out. All biological laboratory assays were carried out after the preleaching water aging process was completed.

\section{Biological Laboratory Assays}

Growth and release of macroalgae (Ulva linza)

A set of multiwall plates was sent to Newcastle University, following water-immersion for 28 days, to assess fouling-release performance of coatings against $U$. linza. A detailed description of 
the method of assessment can be found elsewhere.$^{58}$ Briefly, after leaching, all multiwell plates were equilibrated in $0.22 \mu \mathrm{m}$ filtered artificial seawater (Tropic Marin) for 2 hours. To each well, $1 \mathrm{~mL}$ of spores of $U$. linza suspension was added, adjusted to $3.3 \times 10^{5}$ spores $/ \mathrm{mL}$ in enriched seawater medium. Spores settled on the coated discs were grown for 7 days inside an illuminated incubator at $18^{\circ} \mathrm{C}$ with a $16: 8$ light: dark cycle (photon flux density $45 \mu \mathrm{mol} \cdot \mathrm{m}^{-2} \cdot \mathrm{s}^{-1}$ ). There was no washing to remove unsettled spores after settlement. After 7 days, the biomass generated was assessed from a single row of wells (6) from each plate. Relative adhesion strength was evaluated by exposing two other rows of wells to two different water pressures using a waterjet. ${ }^{59}$. Chlorophyll was extracted by adding $1 \mathrm{~mL}$ DMSO to each well and followed by measuring the fluorescence at $360 \mathrm{~nm}$ excitation and $670 \mathrm{~nm}$ emission. Fluorescence is directly proportional to the biomass present on each coating surface. The removal of $U$. linza at each pressure was compared with the unsprayed wells that were used to determine initial growth. $22,52,59$

\section{Growth and Release of Microalgae (Navicula incerta)}

A laboratory biological assay to evaluate FR properties of coatings towards diatom cells (Navicula incerta) was conducted at NDSU following a similar procedure to that described previously. ${ }^{58,60}$ Briefly, a suspension with $4 \times 10^{5}$ cells $/ \mathrm{mL}$ of $N$. incerta (adjusted to 0.03 OD at absorbance $660 \mathrm{~nm}$ ) in Guillard's F/2 medium was deposited into each well (1 mL per well) and cell attachment was stimulated by static incubation for 2 hours, under ambient conditions, in the dark. Coating surfaces were then subjected to water-jet treatments. ${ }^{59}$ The first column of wells (3 wells) was not water-jetted so that initial cell attachment could be determined and the next column of wells (3 wells) was water-jetted at 20 psi for 10 seconds. Microalgae biomass was quantified by extracting chlorophyll using $0.5 \mathrm{~mL}$ of DMSO and measuring fluorescence of the transferred extracts at an excitation wavelength of $360 \mathrm{~nm}$ and an emission wavelength at $670 \mathrm{~nm}$. The relative fluorescence units (RFU) measured from the extracts was considered to be directly proportional to the biomass remaining on the coating surfaces after water-jetting. Percent removal of attached microalgae was determined from RFUs of non-jetted and water-jetted wells. 


\section{Bacterial (Cellulophaga lytica) Biofilm Adhesion}

Fouling-release properties towards bacteria were evaluated using retention and adhesion assays described previously. ${ }^{22,52,59} \mathrm{~A}$ suspension consisting of the marine bacterium C. lytica at $10^{7}$ cells $/ \mathrm{mL}$ concentration, in artificial seawater (ASW), containing $0.5 \mathrm{~g} / \mathrm{L}$ peptone and $0.1 \mathrm{~g} / \mathrm{L}$ yeast extract was deposited into 24 -well plates $(1 \mathrm{~mL} /$ well). The plates were then incubated statically at $28^{\circ} \mathrm{C}$ for 24 hours. The ASW growth medium was then removed and the coatings were subjected to water-jet treatments. The first column of each coating (3 replicate wells) was not treated and served as the initial amount of bacterial biofilm growth. The second column (3 replicate wells) was subjected to water-jetting at 10 psi for 5 seconds. Following water-jet treatments, the coating surfaces were stained with $0.5 \mathrm{~mL}$ of a crystal violet solution ( $0.3 \mathrm{wt}$. \% in deionized water) for 15 minutes and then rinsed three times with deionized water. After 1 hour of drying at ambient laboratory conditions, the crystal violet dye was extracted from the coating surfaces by adding $0.5 \mathrm{~mL}$ of $33 \%$ acetic acid solution for 15 minutes. The resulting eluates were transferred to a 96 -well plate $(0.15 \mathrm{~mL} / \mathrm{coating}$ replicate) and subjected to absorbance measurements at $600 \mathrm{~nm}$ wavelength using a multi-well plate spectrophotometer. The absorbance values were considered to be directly proportional to the amount of bacterial biofilm present on coating surfaces before and after water-jetting treatments. ${ }^{33}$

\section{Adult Barnacle (Amphibalanus amphitrite) Adhesion}

An adult barnacle reattachment and adhesion assay was used to evaluate the FR properties of the coatings towards macrofoulers. ${ }^{61,62}$ Coatings prepared on 4" x 8" panels after water aging were utilized for this laboratory assay. Barnacles were dislodged from silicone substrates sent from Duke University Marine Laboratory (DUML) in Beaufort, North Carolina, USA, and immobilized on experimental coatings (6 barnacles per coating) using a custom-designed immobilization template. The immobilized barnacles were allowed to reattach and grow for 2 weeks while immersed in an ASW aquarium tank system with daily feedings of brine shrimp Artemia nauplii (Florida Aqua Farms). After the 2-week attachment period, the number of non-attached barnacles was recorded, and the attached barnacles were pushed off (in shear) using a hand-held force gauge mounted onto a semi-automated 
stage. Once the barnacles were dislodged, their basal plate areas were determined from scanned images using Sigma Scan Pro 5.0 software program. Barnacle adhesion strength (MPa) was calculated by taking the ratio of peak force of removal to the basal plate area for each reattached barnacle. To ensure consistency, barnacles of similar sizes were tested. The average barnacle adhesion strength for each coating was reported as a function of the number of barnacles released with a measurable force and that exhibited no visible damage to the basis or shell plates.

\section{Mussels (Geukensia demissa) Adhesion}

Marine mussels were used to evaluate fouling-release performance of the coating using 4" x 8" coated panels. Marine mussels (G. demissa) were provided by the DUML. Each mussel was further prepared for testing purposes by attaching a 4-cm-long acetal plastic rod (product \# 98873A105, McMaster-Carr) perpendicular to the ventral edge, with a $3 \mathrm{M} \AA$ acrylic adhesive (product \# 7467A135, McMaster-Carr). A total of six mussels were allowed to explore the surface of a coating for settlement, followed by placing custom-designed PVC sheets against plastic rods so that mussels were in contact with the surface of a coating. Coatings were analyzed after 3 days of attachment with two feedings of phytoplankton. The total number of mussels that attached by byssus threads was recorded for each surface. A tensile force gauge (mounted to an automated stage, moving at $1 \mathrm{~mm} / \mathrm{s}$ pull rate) attached to a mussel's plastic rod was used to measure the force (Newtons) required to completely remove attached mussels from coating surfaces. The average force for all mussels that were removed from a surface was recorded. The presence of nonattached mussels after a 3-day period indicated good mussel deterrence properties. ${ }^{59,60,63}$

\section{Statistical Analysis}

Analysis of variance for completely randomized design (CRD) (all experimental and control coatings included in this design) was performed in SAS software, version 9.4. The GLM procedure with least-squares means (LS-means) methods was used to determine the difference between means for each treatment group under the CRD design. The analysis compared two response values of interest, fouling-release performance of coatings against barnacles and $U$. linza. 


\section{Coatings Mechanical Assessment}

Stability, adhesion, strength, and flexibility are important properties that are desired for organic coatings. Solvent double rub test, impact test, crosshatch adhesion test, conical mandrel test, pencil hardness, and König pendulum hardness tests were assessed following standard procedures ASTM D5402, ASTM D2794, ASTM D3359, ASTM D522, ASTM D3363, and ASTM D4366. A brief description of these methods is available in the Supporting Information as well.

\section{Results and Discussion}

Amphiphilic coatings have shown an enhanced ability to deter the attachment of a wide range of marine organisms. Therefore, we hypothesized that the addition of amphiphilic additives to a hydrophobic system will modify its surface to become amphiphilic, resulting in improved performance. This study investigated the synthesis of a series of amphiphilic additives based on building blocks of poly(SBMA) and PDMS and their incorporation in a well-established hydrophobic marine coating system the A4-20 siloxane-polyurethane coating. ${ }^{9}$

To synthesize the amphiphilic additives, two components were prepared and characterized beforehand, SBMA monomer and Br-PDMS macroinitiator. SBMA was prepared by the reaction of 2(dimethylamino) ethyl methacrylate with 1,3-propane sultone as illustrated in Scheme 1. The synthesized monomer was characterized by ${ }^{1} \mathrm{H}-\mathrm{NMR}$, FTIR and melting point. The ${ }^{1} \mathrm{H}-\mathrm{NMR}$ data shows all the expected signals corresponding to the structure of the monomer. These include signals from the proton of the carbon-carbon double bond appearing at $5.7 \mathrm{ppm}$ and $6.15 \mathrm{ppm}$, along with other characteristic peaks (Figure S3). The FTIR spectrum showed signals for ${ }^{+} \mathrm{NR}_{4}\left(960 \mathrm{~cm}^{-1}\right), \mathrm{SO}_{3}$ $\left(1060 \mathrm{~cm}^{-1}\right), \mathrm{C}=\mathrm{C}\left(1640 \mathrm{~cm}^{-1}\right)$, and $\mathrm{C}=\mathrm{O}\left(1740 \mathrm{~cm}^{-1}\right)$ as shown in Figure S4, further confirming successful synthesis of the SBMA monomer. A OH shift at $3500 \mathrm{~cm}^{-1}$ was observed due to the hygroscopic nature of the monomer. ${ }^{64}$ Also, the melting point of the monomer was $150{ }^{\circ} \mathrm{C}$, which is within reported values. ${ }^{53}$

Br-terminated PDMS that functions as the ARGET-ATRP macroinitiator was synthesized by substituting the hydroxy functional groups with BIBB as outlined in Scheme 2. A comparison of ${ }^{1} \mathrm{H}-$ 
NMR between virgin PDMS and modified PDMS confirmed the transformation of hydroxyl end groups to bromine as the $-\mathrm{OH}$ signal disappeared at $4 \mathrm{ppm}$, signals for two methyl groups of BIBB appeared at 1.9 ppm (Signal "a" in Figure S5), and signals of hydrogen on a-carbon of original hydroxyl group further de-shielded due to electronegative nature of introduced bromine (signal "b" in Figure S5). Furthermore, the transformation of end groups to bromine was supported by the appearance of $\mathrm{C}=\mathrm{O}$ $\left(1740 \mathrm{~cm}^{-1}\right)$ and disappearance of $\mathrm{OH}\left(3500 \mathrm{~cm}^{-1}\right)$ signals in FTIR (Figure S6).

After the SBMA monomer and Br-terminated PDMS macroinitiator were synthesized, amphiphilic additives were synthesized as shown in Scheme 3. The characteristic ${ }^{1} \mathrm{H}-\mathrm{NMR}$ spectrum of a representative tri-block ABA additive is shown in Figure S7. The nearly disappeared peaks of the proton of the carbon-carbon double bond in SBMA at 5.5-6.5 ppm as well as broad peaks confirmed the polymerization of SBMA with the PDMS macroinitiator. The formation of additive is confirmed by FTIR data in Figure S8 that has indicative signals for both poly(SBMA) and PDMS segments: $\mathrm{C}=\mathrm{O}$ at $1740 \mathrm{~cm}^{-1}$, Si-O at $1164 \mathrm{~cm}^{-1}, \mathrm{SO}_{3}$ at $1060 \mathrm{~cm}^{-1}$, and ${ }^{+} \mathrm{NR}_{4}$ at $960 \mathrm{~cm}^{-1}$.

The synthesized additives were then added into the A4-20 SiPU system in 0.2 wt.\%, 1 wt.\%, and $5 \mathrm{wt} . \%$. A series of contact angle measurements offered insights into the effect of the additives on surface properties. The water contact angles (WCAs) of all the coatings were dynamic in nature dropping as a function of time within a 15-minute period (Figure 1A). We attribute the change in WCAs to the interaction of the water droplet with hydrophilic poly(SBMA) chains that started to swell after being exposed to a "good" solvent, ${ }^{65}$ facilitating the spreading of the water droplet. In contrast, the unmodified A4-20 control coating did not show any dynamic behavior as its WCA remained almost unchanged over the same time period. This observation supports the theory that amphiphilic additives self-stratified to the surface and modified the surface properties of the A4-20 system. Also, the data indicates that higher MW poly(SBMA) chains on an additive lead to a more dynamic surface, given PDMS MW remains constant. For example, this trend can be observed among coatings containing additives $500-1 \mathrm{kand} 2.5 \mathrm{k}-1 \mathrm{k}$ (systems 3 and 9 ), where poly(SBMA) MW increases from $500 \bar{M}_{n}$ to $2500 \bar{M}_{n}$. However, a combination of PDMS and poly(SBMA) factors suggest both the ratio of hydrophilic and hydrophobic moieties as well as MW of these moieties affect the extent of dynamic 
behavior. For example, the system containing additive $2.5 \mathrm{k}-10 \mathrm{k}-2.5 \mathrm{k}$ (formulation 26 ) is noticeably more dynamic than the system with $1 \mathrm{k}$-1k additive (formulation 6) - while the hydrophilic ratio of both additives was $50 \%$ but size of their hydrophilic chains was different (Table 2).

The higher amount of an additive in a system (i.e. $1 \mathrm{wt} \%$ vs 5 w.\%) results in a lower initial WCA and more change over time as exemplified for additive 1k-1k-1k (Figure S9). Methylene iodide contact angles (MICA) were slightly less dynamic as expected due to its nonpolar properties, but additive-containing systems still displayed changes in comparison to the A4-20 system (Figure 1A). Surface energy values for the coatings initially lay between $22-27 \mathrm{mN} / \mathrm{m}$ and increased considerably after 15 minutes, unlike the A4-20 system. This increase correlates with the WCAs and MICAs; the higher the change in contact angle values over time, the higher the change in surface energy for a coating (Figure 1B). An unchanged or slightly marginal increase of surface energy for all the coatings was observed after 28 days of water aging, indicating that the coatings were stable, and that a significant loss of the additives was not observed (Figure 1B). Overall, the contact angle data suggested that the poly(SBMA)-based additives are accessible on the surface since the non-dynamic hydrophobic surface of SiPU A4 exhibits a dynamic characteristic after introduction of amphiphilic additives. 


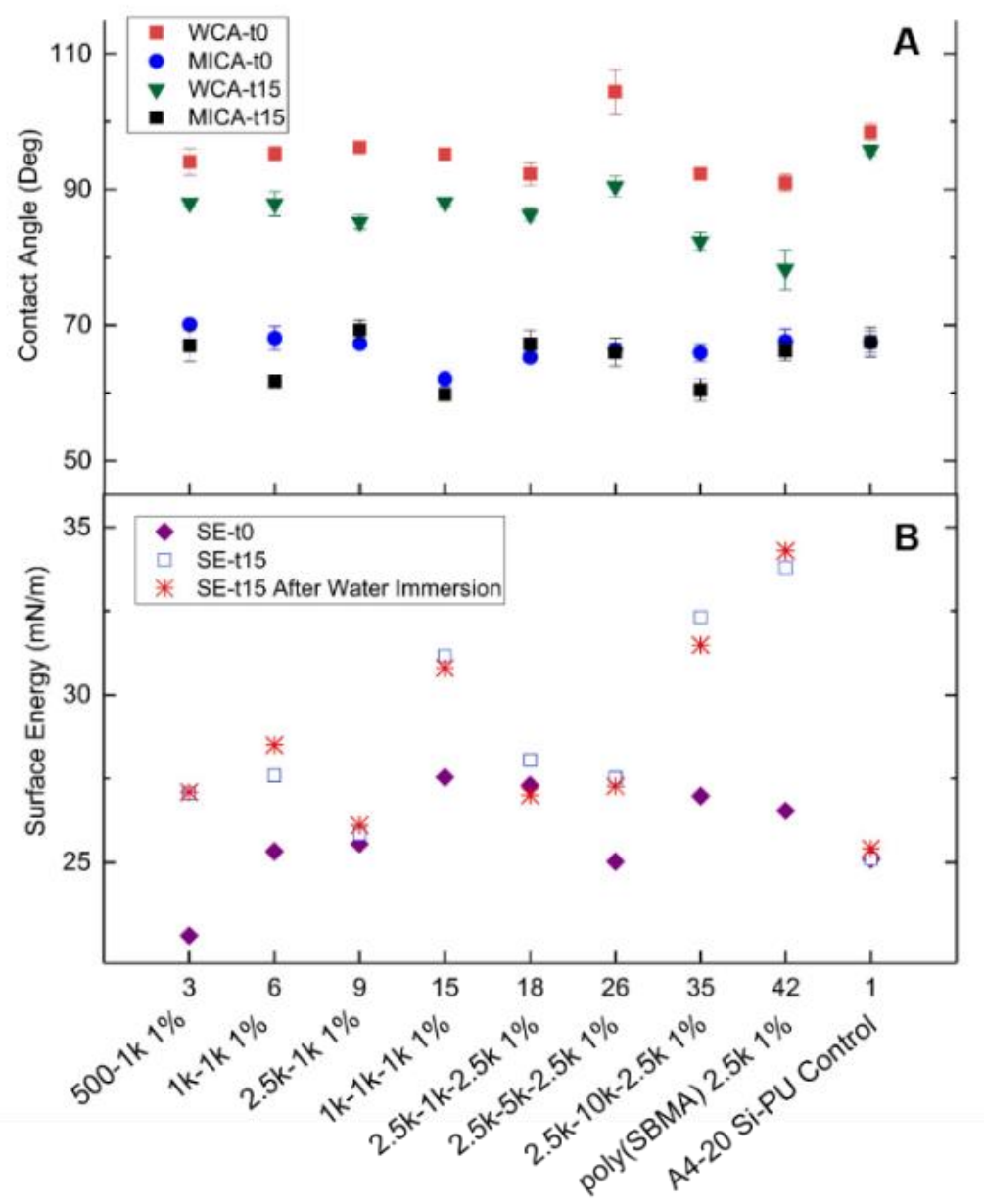

Figure 1. Contact angle data for selected additive-containing A4-20 systems. (A) Water contact angles (WCA) and methylene iodide contact angles (MICA) as a function of time at 0 minute and 15 minutes. (B) Surface energy (SE) values at 0 minute and 15 minutes before water immersion and at 15 minutes after 28 days water immersion, calculated by Owens-Wendt method utilizing average WCAs and MICAs for each coating. The X-axis is labeled to indicate both the coating number and additive type/composition.

All selected coatings were analyzed by AFM to determine morphology of the surfaces. Figure 2 and Figure S10 display phase and height AFM images, respectively. Theoretically, lighter areas with higher phase angles indicate the presence of softer materials like PDMS, while darker areas suggest the presence of harder materials like poly(SBMA) or polyurethane. To this effect, the AFM phase images for additive-containing coatings show very heterogeneous surfaces that possess many microdomains in comparison to the A4-20 system. These images support the presence of the incorporated additives on the surface as is evident through differences in surface morphology 
compared to that of the A4-20 system. Coatings that contain $2.5 \mathrm{k}$ poly(SBMA) blocks as part of their incorporated additives show domains that are stretched throughout the surface, while coatings with shorter poly(SBMA) chains (500 and $1 \mathrm{k} \bar{M}_{n}$ ) show domains that are smaller, localized and circular. We attempted to capture AFM images in the hydrated state, but it was not feasible after many unsuccessful trials, while systems with poly(ethylene glycol) (PEG)-based moieties on the surface did not exhibit this problem. It is likely that the reason for the difficulties in taking hydrated AFM images occurs because the poly(SBMA) attracts up to 8 times more water molecules than PEG, indirectly suggesting SBMA-based domains are present on the surface as expected.

The surfaces of the coatings were also characterized with ATR-FTIR. The spectra for all the additive-containing coatings were very similar, and all the coatings possessed the signature peak for $\mathrm{SO}_{3}$, confirming the presence of the poly(SBMA) moieties near the interface for formulations. As an example, Figure 3 shows plots for a series of coatings containing $2.5 \mathrm{k}-1 \mathrm{k}-2.5 \mathrm{k}$ additive at varying concentrations of $0.2,1.0,5.0$, and $10.0 \mathrm{wt} . \%$ (formulations $17,18,19,38$, respectively) in comparison to the spectrum of unmodified SiPU A4-20 system. The signal that indicated the presence of poly(SBMA)-containing additives on a surface was for $\mathrm{SO}_{3}$ at $1060 \mathrm{~cm}^{-1}$ (Figure 3 - highlighted red) in correlation with SBMA monomer FTIR (Figure S4). This conclusive $\mathrm{SO}_{3}$ peak appeared as a stretching between the two well-recognized peaks of siloxane (Figure 3 - highlighted green). The remaining characteristic peaks of A4-20 were observed for all coatings; for example, the secondary amine peak of urethane linkage due to crosslinking reaction of isocyanate and polyol at $3350 \mathrm{~cm}^{-1}$. 
$3(500-1 \mathrm{k} 1 \%)$

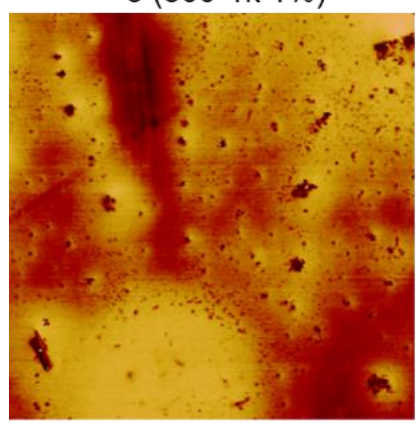

15 (1k-1k-1k 1\%)

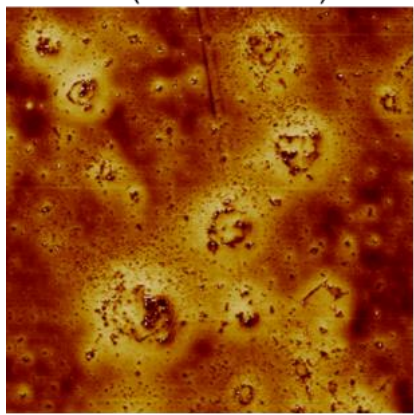

35 (2.5k-10k-2.5k 1\%)

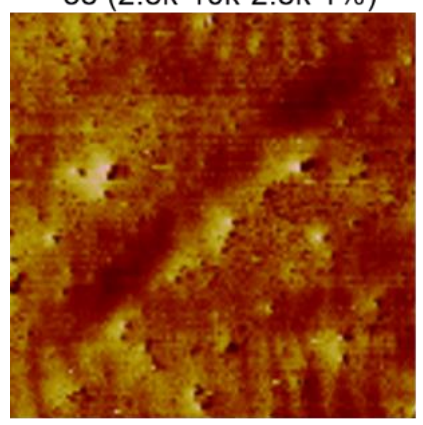

$6(1 \mathrm{k}-1 \mathrm{k} 1 \%)$

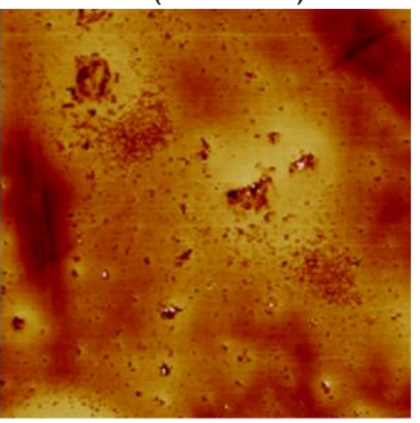

$18(2.5 \mathrm{k}-1 \mathrm{k}-2.5 \mathrm{k} 1 \%)$

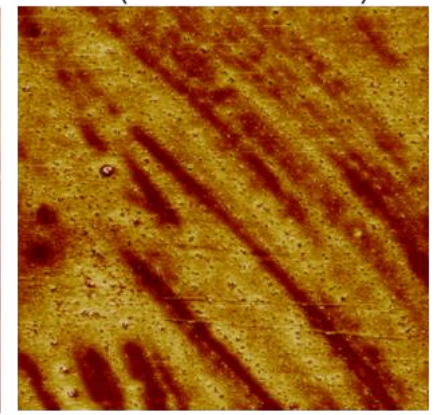

42 (poly(SBMA) 1\%)

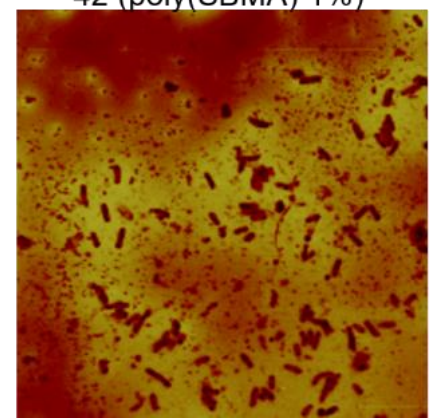

$9(2.5 \mathrm{k}-1 \mathrm{k} 1 \%)$



$26(2.5 \mathrm{k}-5 \mathrm{k}-2.5 \mathrm{k} 1 \%)$

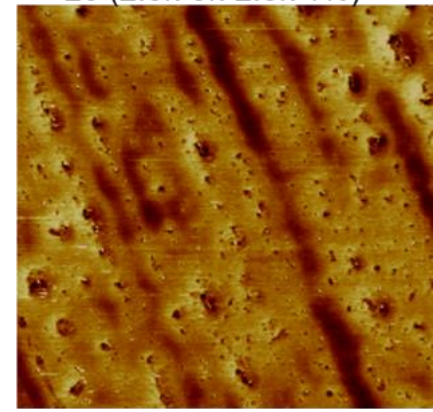

1 (A4-20 SiPU Control)

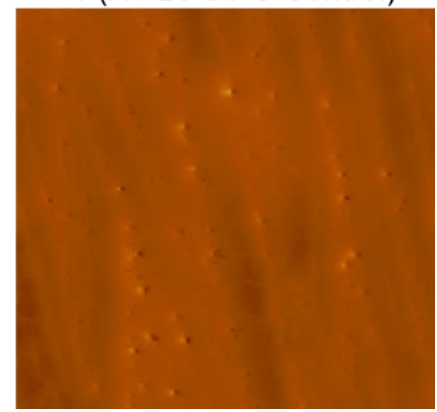

Figure 2. AFM phase images of A4-20 systems containing surface-modifying amphiphilic additives for a scan area of $50 \mu \mathrm{m} \times 50 \mu \mathrm{m}$. Each label reflects the coating number and its additive type and composition. 


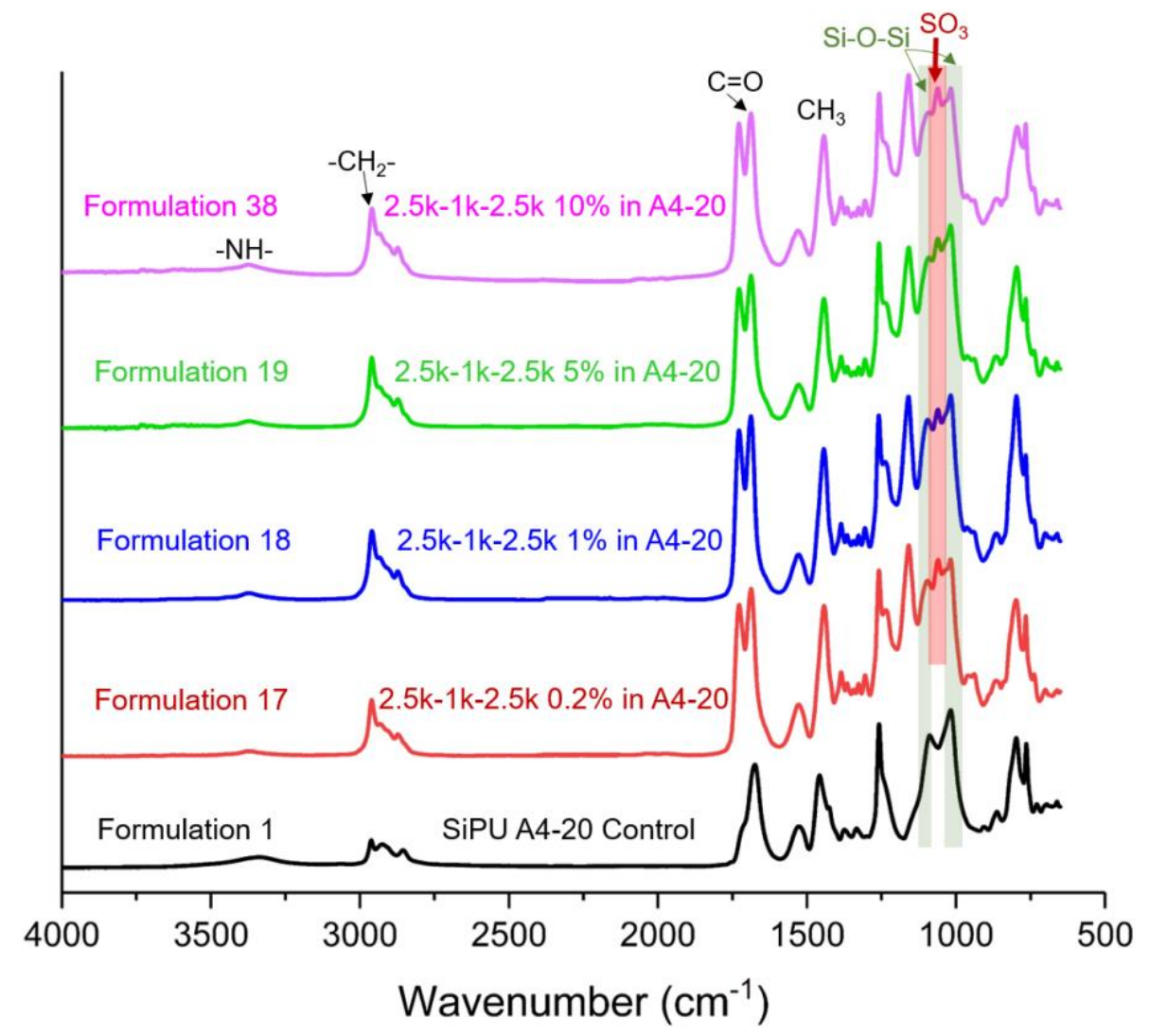

Figure 3. ATR-FTIR spectra for SiPU A4-20 control coating and its modified versions (coatings $17,18,19$, and 38 where $2.5 \mathrm{k}-1 \mathrm{k}-2.5 \mathrm{k}$ additive is added at $0.2,1.0,5.0$, and $10.0 \mathrm{wt}$. respectively). The labels are colored and in-line with each spectrum to identify the formulations. The additive-modified systems were normalized using the $\mathrm{C}-\mathrm{O}-\mathrm{C}$ signal at $\mathrm{ca}$. $1200 \mathrm{~cm}^{-1}$.

All biological laboratory assays to evaluate fouling-release performance of marine coatings were conducted after 28 days of water immersion. Before any experiments, the toxicity of coatings leachates was assessed to ensure coatings a were non-toxic (using $C$. lytica and $N$. incerta) as described elsewhere. ${ }^{66}$ Briefly, overnight extracts of the coatings were gathered and inoculated with algae and bacteria. The growth of algae and bacteria was quantified after 48 hours by fluorescence of chlorophyll and crystal violet absorbance, respectively. The measurements were compared against positive and negative growth controls. Bioassay of leachates from the coatings was negative (data not reported), and the coatings underwent further evaluations.

The eight formulations outlined in Table 2 were shortlisted out of the 43 formulations tabulated in Table S1 after preliminary fouling-release assessments against $C$. lytica (Figure S1) and U. linza 
(Figure S2), and these eight were further investigated against $U$. linza, barnacles, and mussels. Overall, the data in Figures $\mathbf{S 1}$ and $\mathbf{S} 2$ shows that systems with additives where their backbone was composed of $1,000 \bar{M}_{n}$ PDMS performed relatively better than additives with other sizes of PDMS. However, to better compare and understand the effect of prepared additives, the systems were not shortlisted solely based on their performance, but rather in a systematic method so various factors could be compared and contrasted such as effect of poly(SBMA) MW, effect of number of polymeric blocks, and extent of additive hydrophilic-hydrophobic balance.

Ulva linza has been widely reported as a common biofouling macroalga. Multiwall plates containing coating formulations were utilized to assess their performance against $U$. linza sporelings. Wettability of a surface influences growth and adhesion strength of $U$. linza. ${ }^{67-69}$ The literature reports that $U$. linza generally adheres more strongly to moderately hydrophilic surfaces than on hydrophobic surfaces. Although all the amphiphilic surfaces after water immersion were more hydrophilic than the unmodified A4-20 coating, the inclusion of the extremely hydrophilic zwitterions may have a destabilizing effect on the adhesive bond. In order for the algal adhesive to form a bond with the substrate, water must be displaced from the joining surfaces and this can be difficult to achieve around extremely hydrophilic surface groups such as ones containing zwitterions. Fouling-release data for $U$. linza are presented in Figure 4, displaying growth (red color) and release at two water pressure levels (blue and green colors). Growth data supports the reported literature that the settlement of spores of $U$. linza is lower on amphiphilic surfaces (all additive-containing coatings). Also, the release performance for all modified coatings was superior to the original A4-20 coating, indicating that incorporation of poly(SBMA)-PDMS-based additives did contribute to better FR properties. A significant difference between the types of additives was not observed, disregarding the effect of number and size of polymeric blocks. All the modified SiPU A4 coatings also showed less initial settlement of $U$. linza than the commercial controls. Release of $U$. linza for all the modified coatings reached a comparable and desirable performance similar to the top-performing commercial controls such as T2 at 10 psi or IS 1100 at both 10 psi and 16 psi water pressures. Analysis of variance (ANOVA), considering the formulations as completely randomized design, indicated that all 
of the additive-containing SiPU A4 coatings (systems 3, 6, 9, 15, 18, 26, 35, and 42) had significantly improved fouling release for $U$. linza in comparison to A4-20 coating control system (comparison Pvalues $<0.05$, Tukey's method, Table S2).



Figure 4. U. linza data for coatings: biofilm growth (red bars) and its biomass remaining after waterjet at 10 psi (blue bars) and 16 psi (green bars). The X-axis is labeled to name both experimental and control coatings; additive composition is mentioned for each experimental system as well.

Diatom ( $N$. incerta) is a slime-forming microalga and has a higher attachment rate and strength of adhesion on hydrophobic surfaces than hydrophilic surfaces. ${ }^{67,70}$ The extent of diatom biofouling and its release appeared to be relatively unchanged for all formulated coatings after introducing the amphiphilic additives to the coating system (Figure 5). This can be attributed to the fact that all the coatings are intrinsically hydrophobic while a small amount of hydrophilicity is introduced to a surface. The release of diatoms from the modified surfaces was similar, or slightly less, than the control A4-20 system. The observed trend was that as the hydrophilic portion on an additive increased, the release of diatoms for modified coatings decreased slightly. Coatings with $500-$ $1 \mathrm{k}, 1 \mathrm{k}-1 \mathrm{k}, 2.5 \mathrm{k}-1 \mathrm{k}$, and $1 \mathrm{k}-1 \mathrm{k}-1 \mathrm{k}$ additives (systems 3, 6, 9, and 15) exhibited a performance comparable to several commercial systems including T2 and IS 700. However, fewer diatoms were 
released from coatings that contained additives $2.5 \mathrm{k}-5 \mathrm{k}-2.5 \mathrm{k}, 2.5 \mathrm{k}-10 \mathrm{k}-2.5 \mathrm{k}$, and poly(SBMA) (systems 26, 35, and 42). The incorporated additives in coatings 26 and 35 contained higher content of PDMS (lower poly(SBMA) content); thus, it may be posited that the higher hydrophobicity of the additive repressed the desired hydrophilic effect (Table 2). To summarize, most of the amphiphilic additives did not have a detrimental impact on the FR performance of SiPU A4-20 system against $N$. incerta.

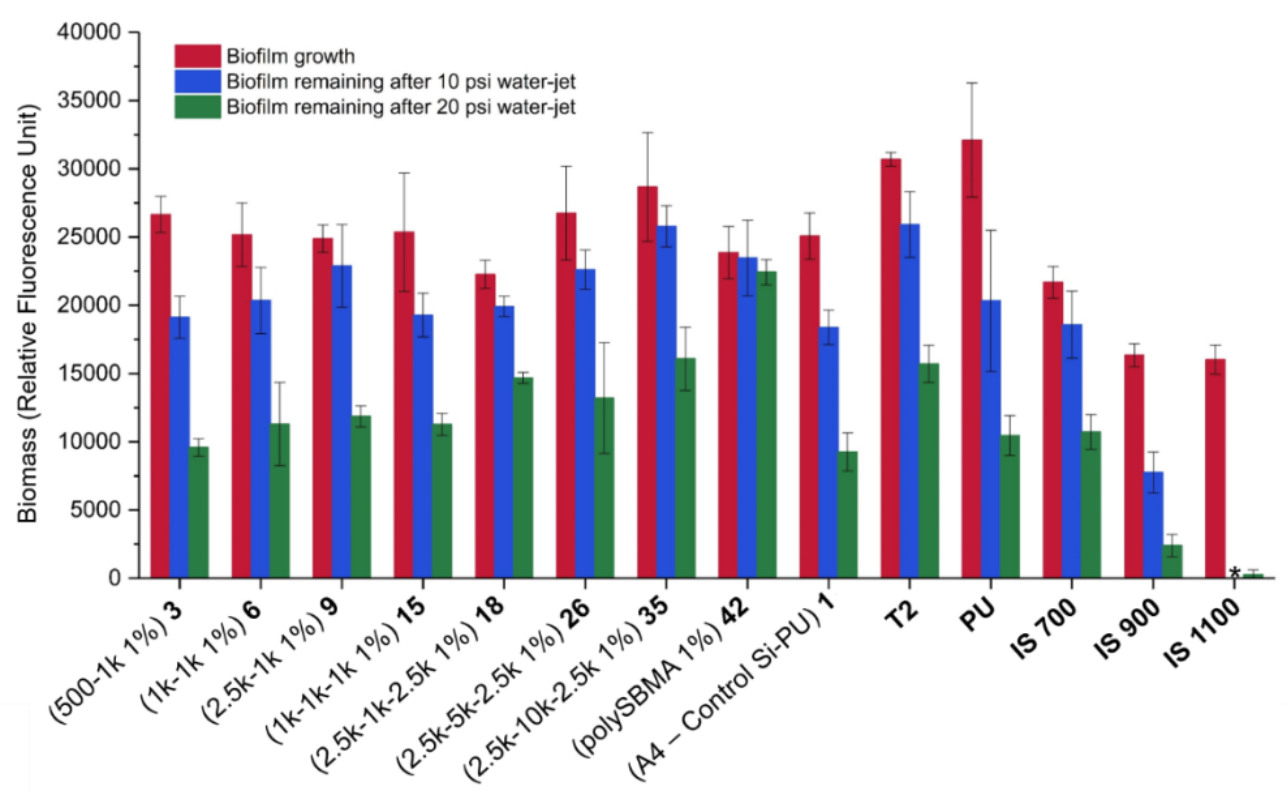

Figure 5. $N$. incerta data for coatings: biofilm growth (red bars) and its biomass remaining after waterjet at 10 psi (blue bars) and 20 psi (green bars). The X-axis is labeled to name both experimental and control coatings; additive composition is mentioned for each experimental system as well. *Data missing due to processing error.

C. Iytica is another marine biofouling organism (bacterium) and known to attach to a wide range of hydrophilic and hydrophobic surfaces. ${ }^{3}$ The collected data in Figure 6 indicates the extent of biofouling and release of the shortlisted systems. The growth of $C$. lytica film for coatings with additives composed of $1000 \bar{M}_{n}$ PDMS in their backbone (coatings 3, 6, 9, 15, and 18) was similar to the A4-20 control system, while systems containing $5000 \bar{M}_{n}$ or 10,000 $\bar{M}_{n}$ PDMS showed relatively higher biofouling. The $C$. lytica film grew considerably more on commercial controls such as IS 700, IS 
900 , and IS 1100 . The release of biofilm at both 10 psi and 20 psi water-jetting pressure showed promising performance. At 10 psi, all modified coatings had a similar or slightly better performance (except coatings 35 and 42) than the A4-20 control system, while demonstrating a better performance than outlined commercial controls. Changing the water pressure to $20 \mathrm{psi}$ did not increase the release of $C$. lytica from the surface of investigated coatings, except for IS 1100 . These results suggest that the introduction of amphiphilic additives caused a slight improvement in the performance of A4-20 system (i.e. coatings $3,6,9,15$, and 18 ). This data implies that the ratio of hydrophilic and hydrophobic moieties on a surface affects fouling-release performance. The hydrophilic portion on an additive is a key factor for tuning the surfaces of a hydrophobic system.

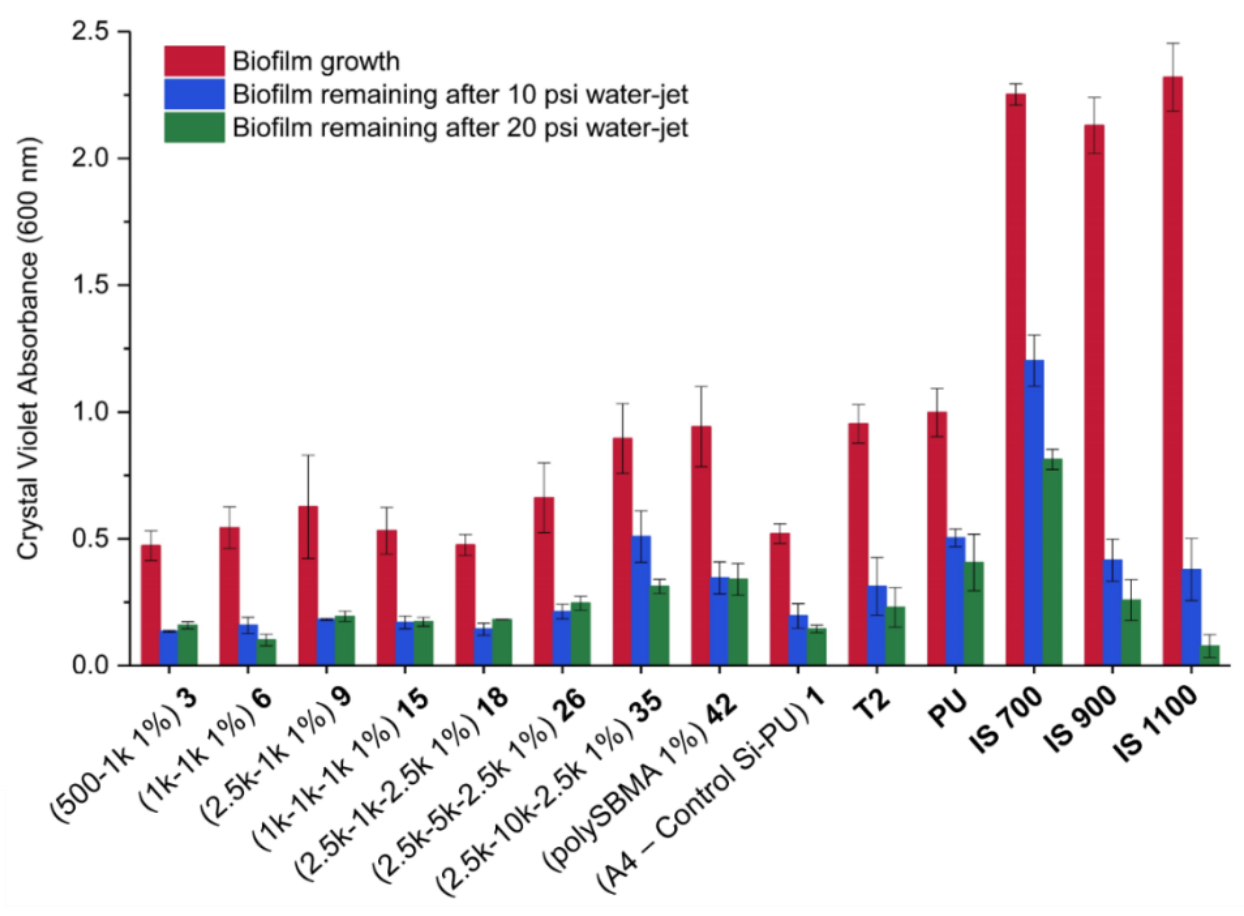

Figure 6. C. lytica data for coatings: biofilm growth (red bars) and its biomass remaining after waterjet at 10 psi (blue bars) and 20 psi (green bars). The X-axis is labeled to name both experimental and control coatings; additive composition is mentioned for each experimental system as well.

Macrofouling organisms such as barnacles and mussels are major marine biofouling organisms. ${ }^{2,71}$ Different species of barnacle have different affinities for surfaces, limiting options to 
basic surface affinity rule. ${ }^{3,72-75}$ For example, Amphibalanus amphitrite prefers hydrophilic surfaces while it still can settle on hydrophobic surfaces. ${ }^{61,62,76,77}$ Adhesion strength of barnacles (measured by a push-off test) was substantially lower on the additive-containing coatings compared to the unmodified A4-20 system (Figure 7). Also, the number of reattached barnacles on a coating differed among systems. This is shown in Figure 7 as the ratio of the number of reattached barnacles over the six barnacles used for evaluation. Several systems such as coatings 6, 9, and 15 demonstrated similar performance to commercial coatings. No barnacle on any coatings was broken as a result of the push-off test. Coating 42, containing the poly(SBMA) additive, deterred the settlement of barnacles, outperforming all investigated and commercial coatings. Analysis of variance (ANOVA), considering the formulations in a completely randomized design, revealed that several systems (coatings $6,9,15,26,35$, and 42) had significantly improved fouling-release properties for barnacles compared to the unmodified SiPU A4-20 control system (comparison P-values $<0.05$, Fisher's method, Table S2). Furthermore, we noticed that the number of reattached barnacles on a surface differed with the ratio of hydrophilic content in the backbone of the amphiphilic additive (Figure 8). As the hydrophilic content of an additive increased, the number of reattached barnacles decreased. Once the additive was $100 \%$ hydrophilic (the poly (SBMA) additive), no barnacles re-attached. This trend may be a useful tool for designing coating systems that deter initial settlement of barnacles. The hydrophilic content of the additives is also outlined in Table 2. 


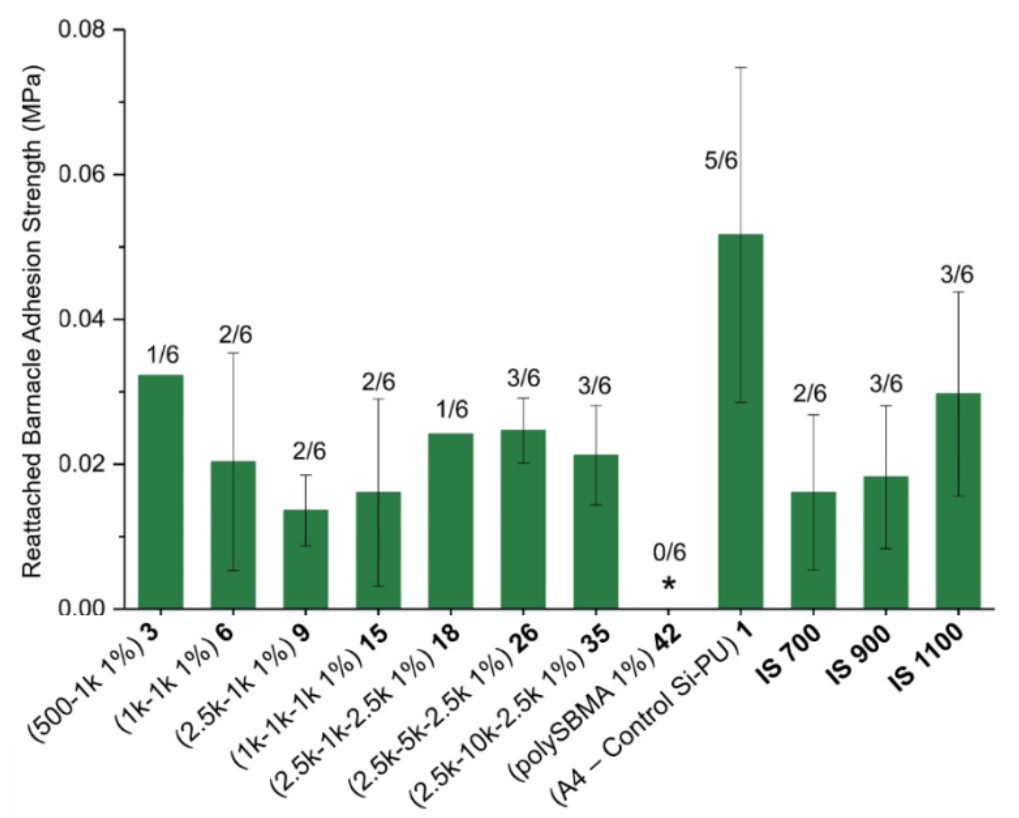

Figure 7. Reattached barnacle ( $A$. amphitrite) adhesion strength. Six barnacles were used for each reattachment study. The number of reattached barnacles out of six is labeled for each system as a ratio (* indicates no barnacle was attached). The X-axis is labeled to name both experimental and control coatings; additive composition is mentioned for each experimental system as well.

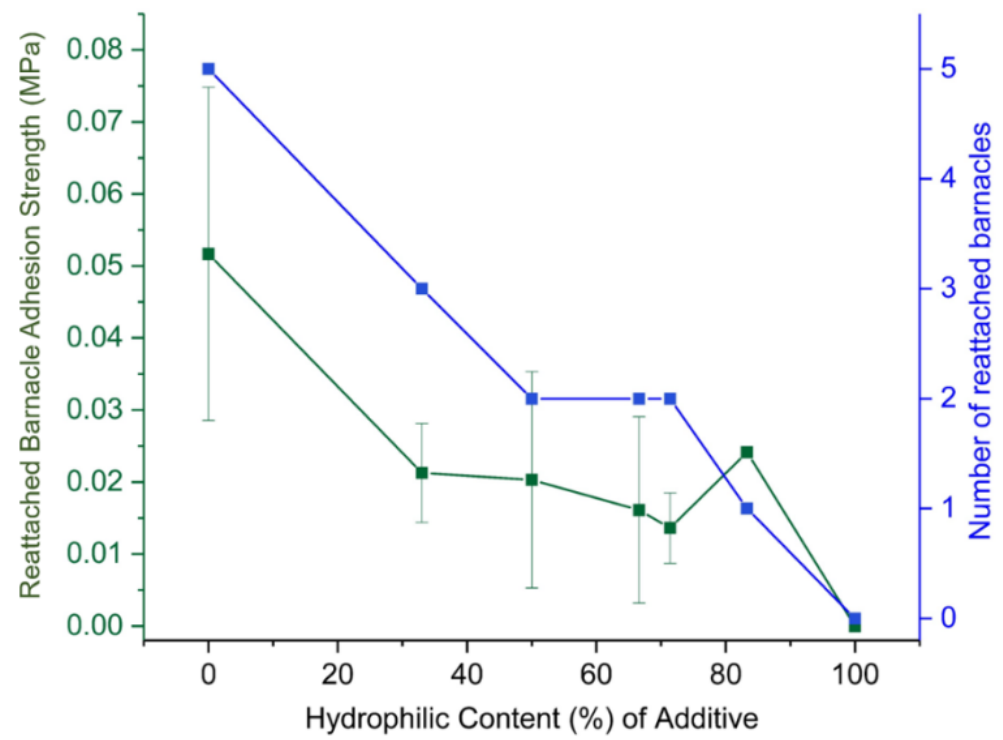

Figure 8. Relationship between number of reattached barnacles ( $A$. amphitrite) and hydrophilic content of the additive. Blue line displays number of barnacles. Green line shows average adhesion strength based on the number of successfully reattached barnacles (with a standard deviation). 
Adult mussels preferentially attach by byssus adhesion to hydrophilic over hydrophobic surfaces. ${ }^{3,16}$ All of the additive-modified and unmodified A4-20 coating systems prevented mussel attachment (Figure 9). This suggests that amphiphilic additives did not alter the already good performance of the A4-20 coating, indicating no detrimental effect. In comparison, the commercial coatings, IS 700 and IS 1100 , did not perform as well.

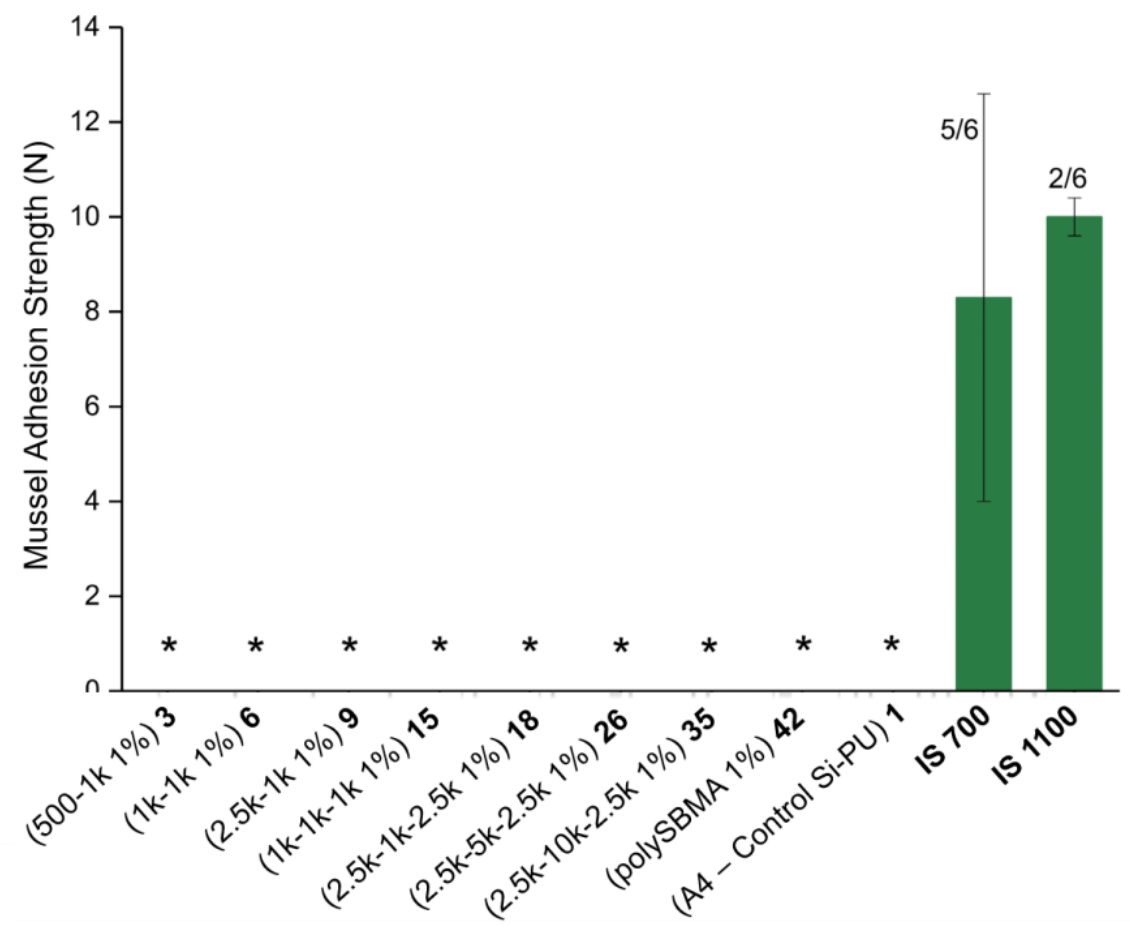

Figure 9. Marine mussel (G. demissa) adhesion strength. Six mussels were used for each coating. The number of attached mussels out of six is labeled for each system as a ratio (* indicates no mussel was attached). Each bar shows the average adhesion strength based on the number of successfully attached mussels. The X-axis is labeled to name both experimental and control coatings; additive composition is mentioned for each experimental system as well.

Coating evaluation tests were performed on the A4 coating and the modified versions containing the amphiphilic additives. Overall, the assessments indicated there was no detrimental effect on bulk properties of the base coating due to addition of the additives. The evaluated properties were relatively similar for all 43 formulations regardless of the amount of added additive or type of added additive. Table 3 highlights properties of coating systems that contain additive $2.5 \mathrm{k}-1 \mathrm{k}-2.5 \mathrm{k}$ at $0.2,1.0,5.0$, and $10.0 \mathrm{wt} \%$, indicating that the properties of the coatings are all very similar. 
Table 4. Mechanical properties of select formulated coatings containing additive $2.5 \mathrm{k}-1 \mathrm{k}-2.5 \mathrm{k}$.

\begin{tabular}{|c|c|c|c|c|c|c|c|c|}
\hline Formulation & $\begin{array}{c}\text { Additive } \\
\text { amount } \\
\text { (wt. \%) }\end{array}$ & $\begin{array}{c}\text { MEK } \\
\text { Double } \\
\text { Rubs }\end{array}$ & $\begin{array}{c}\text { Forward } \\
\text { Impact } \\
\text { (in-lb) }\end{array}$ & $\begin{array}{c}\text { Reverse } \\
\text { Impact } \\
\text { (in-lb) }\end{array}$ & $\begin{array}{c}\text { Conical } \\
\text { Mandrel } \\
\text { (mm) }\end{array}$ & $\begin{array}{c}\text { Crosshatch } \\
\text { Adhesion }\end{array}$ & $\begin{array}{c}\text { Pencil } \\
\text { Hardness }\end{array}$ & $\begin{array}{c}\text { König } \\
\text { Hardness } \\
\text { (s) }\end{array}$ \\
\hline 1 (A4 control) & 0.0 & $>400$ & 112 & 92 & No fail & $5 \mathrm{~B}$ & $5 \mathrm{H}$ & 23 \\
\hline 17 & 0.2 & $>400$ & 108 & 96 & No fail & $5 \mathrm{~B}$ & $4 \mathrm{H}$ & 24 \\
\hline 18 & 1.0 & $>400$ & 112 & 96 & No fail & $5 \mathrm{~B}$ & $5 \mathrm{H}$ & 21 \\
\hline 19 & 5.0 & $>400$ & 116 & 92 & No fail & $5 \mathrm{~B}$ & $5 \mathrm{H}$ & 26 \\
\hline 38 & 10.0 & $>400$ & 116 & 96 & No fail & $5 \mathrm{~B}$ & $5 \mathrm{H}$ & 24 \\
\hline
\end{tabular}

\section{Conclusion}

A series of block copolymer amphiphilic additives containing poly(SBMA) and PDMS blocks were prepared. Unlike many other studies that utilize conventional and surface-initiated ATRP to attain zwitterionic surfaces, we introduced a facile preparation procedure through ARGET-ATRP technique that enables combination of poly(SBMA) and PDMS blocks and facilitates incorporation of these amphiphilic additives into many systems easily and non-covalently. The poly(SBMA)-PDMS additives were introduced into a hydrophobic marine siloxane-polyurethane coating system, known as A4-20, with an objective of attaining an amphiphilic surface. Contact angle experiments indicated that the amphiphilic additives were present on the surface and did not leach out of the coating after 28 days of water immersion, as the values remained unchanged. AFM images for additive-containing systems illustrated the presence of heterogeneous microdomains on the surface that were absent for the A4-20 coating due to its homogenous surface composed of PDMS. Also, ATR-FTIR further substantiated the self-stratification of the amphiphilic additives into a surface by showing a signal for the $\mathrm{SO}_{3}$ signature of poly(SBMA). In general, considering the performance of modified SiPU A4-20 coatings versus the unmodified A4-20 and commercial controls, it can be summarized that additives $1 \mathrm{k}-1 \mathrm{k}, 2.5 \mathrm{k}-1 \mathrm{k}, 1 \mathrm{k}-1 \mathrm{k}-1 \mathrm{k}$, and $2.5 \mathrm{k}-1 \mathrm{k}-2.5 \mathrm{k}$ (systems $6,9,15,18$ ) outstandingly boosted the performance of base SiPU A4-20 system against several representative marine organisms such as macroalgae (U. linza) and barnacle ( $A$. amphitrite), while these additives did not cause detrimental effects towards deterrence of other marine organisms, including diatom ( $N$. incerta), bacteria $(C$. lytica), and mussel (G. demissa). Since the well-performing poly(SBMA)-PDMS additives contained 
PDMS segments with a molecular weight of $1000 \bar{M}_{n}$ and a hydrophilic ratio within $~ 50-80 \%$, it can be concluded that several factors should be considered when such amphiphilic additives are being designed to improve the performance of hydrophobic marine coatings: 1) The use of a PDMS block with a molecular weight of $1000 \bar{M}_{n}$ is in preference to higher molecular weights; 2) The hydrophilic portion should be between $50 \%$ and $80 \%$ to provide the desired amphiphilicity on a surface; and 3 ) The poly(SBMA) block size does not necessarily affect the effectiveness of an amphiphilic additive.

\section{Acknowledgements}

This work was supported by the United States Navy's Office of Naval Research under grant number N00014-16-1-3064 and N00014-16-1-3125 (ASC and JAF). We would like to also acknowledge Dr.

Daniel Rittschof and Beatriz Orihuela of Duke University for supplying adult barnacles and mussels for biofouling studies.

\section{Supporting Information}

Supporting Information is available that includes the list of studied coatings, biological assays data for C. lytica and $N$. incerta, FTIR and ${ }^{1} \mathrm{H}-\mathrm{NMR}$ data, surface characterizations, and statistical analysis.

\section{Data Availability}

The raw data required to reproduce these findings are available on request to the corresponding author.

\section{References}

1. Callow, J. A.; Callow, M. E., Trends in the development of environmentally friendly fouling-resistant marine coatings. Nature Communications 2011, 2 (1), 244-244.

2. Callow, M. E.; Callow, J. E., Marine biofouling: a sticky problem. Biologist 2002, 49 (1), 10-14.

3. Lejars, M. n.; Margaillan, A.; Bressy, C., Fouling release coatings: a nontoxic alternative to biocidal antifouling coatings. Chemical reviews 2012, 112 (8), 4347-4390.

4. Magin, C. M.; Cooper, S. P.; Brennan, A. B., Non-toxic antifouling strategies. Materials today 2010, 13 (4), 36-44.

5. Yebra, D. M.; Kiil, S.; Dam-Johansen, K., Antifouling technology—past, present and future steps towards efficient and environmentally friendly antifouling coatings. Progress in Organic Coatings 2004, 50 (2), 75-104.

6. Champ, M. A., A review of organotin regulatory strategies, pending actions, related costs and benefits. Science of the total Environment 2000, 258 (1-2), 21-71. 
7. Konstantinou, I. K.; Albanis, T. A., Worldwide occurrence and effects of antifouling paint booster biocides in the aquatic environment: a review. Environment International 2004, 30 (2), 235-248.

8. Sommer, S.; Ekin, A.; Webster, D. C.; Stafslien, S. J.; Daniels, J.; VanderWal, L. J.; Thompson, S. E. M.; Callow, M. E.; Callow, J. A., A preliminary study on the properties and fouling-release performance of siloxane-polyurethane coatings prepared from poly(dimethylsiloxane) (PDMS) macromers. Biofouling 2010, 26 (8), 961-972.

9. Bodkhe, R. B.; Thompson, S. E. M.; Yehle, C.; Cilz, N.; Daniels, J.; Stafslien, S. J.; Callow, M. E.; Callow, J. A.; Webster, D. C., The effect of formulation variables on fouling-release performance of stratified siloxane-polyurethane coatings. Journal of Coatings Technology and Research 2012, 9 (3), 235-249.

10. Pade, M.; Webster, D. C., Self-stratified siloxane-polyurethane fouling-release marine coating strategies: A review. In Marine Coatings and Membranes, Mittal, V., Ed. Central West Publishing: Australia, 2019; pp 1-36.

11. Iguerb, O.; Poleunis, C.; Mazeas, F.; Compere, C.; Bertrand, P., Antifouling properties of poly(methyl methacrylate) films grafted with poly(ethylene glycol) monoacrylate immersed in seawater. Langmuir 2008, 24 (21), 12272-12281.

12. Heuberger, M.; Drobek, T.; Spencer, N. D., Interaction forces and morphology of a protein-resistant poly(ethylene glycol) layer. Biophysical Journal 2005, 88 (1), 495-504.

13. Jeon, S. I.; Lee, J. H.; Andrade, J. D.; De Gennes, P. G., Protein-surface interactions in the presence of polyethylene oxide: I. Simplified theory. Journal of Colloid and Interface Science 1991, 142 (1), 149-158.

14. Szleifer, I., Polymers and proteins: interactions at interfaces. Current Opinion in Solid State and Materials Science 1997, 2 (3), 337-344.

15. Prime, K. L.; Whitesides, G. M. Adsorption of proteins onto surfaces containing end-attached OHgo(ethylene oxide): A model system using self-assembled monolayers; 1993; pp 10714-10721.

16. Galhenage, T. P.; Webster, D. C.; Moreira, A. M. S.; Burgett, R. J.; Stafslien, S. J.; Vanderwal, L.; Finlay, J. A.; Franco, S. C.; Clare, A. S., Poly(ethylene) glycol-modified, amphiphilic, siloxane- polyurethane coatings and their performance as fouling-release surfaces. Journal of Coatings Technology and Research 2017, 14 (2), 307-322.

17. Zheng, Z.; Shengfu, C.; Yung Chang, a.; Jiang, S., Surface grafted sulfobetaine polymers via atom transfer radical polymerization as superlow fouling coatings. Journal of Physical Chemistry B 2006, 110 (22), 10799-10804.

18. Jiang, S.; Cao, Z., Ultralow-fouling, functionalizable, and hydrolyzable zwitterionic materials and their derivatives for biological applications. Advanced Materials 2010, 22 (9), 920-932.

19. Wu, C.-J.; Huang, C.-J.; Jiang, S.; Sheng, Y.-J.; Tsao, H.-K., Superhydrophilicity and spontaneous spreading on zwitterionic surfaces: carboxybetaine and sulfobetaine. RSC Advances 2016, 6 (30), 2482724834.

20. Zhang, Z.; Finlay, J. A.; Wang, L.; Gao, Y.; Callow, J. A.; Callow, M. E.; Jiang, S., PolysulfobetaineGrafted Surfaces as Environmentally Benign Ultralow Fouling Marine Coatings. Langmuir 2009, 25 (23), 1351613521. 
21. Liu, P.; Huang, T.; Liu, P.; Shi, S.; Chen, Q.; Li, L.; Shen, J., Zwitterionic modification of polyurethane membranes for enhancing the anti-fouling property. Journal of Colloid and Interface Science 2016, 480, 91-101. 22. Bodkhe, R. B.; Stafslien, S. J.; Daniels, J.; Cilz, N.; Muelhberg, A. J.; Thompson, S. E. M.; Callow, M. E.; Callow, J. A.; Webster, D. C., Zwitterionic siloxane-polyurethane fouling-release coatings. Progress in Organic Coatings 2015, 78, 369-380.

23. Wu, J.; Lin, W.; Wang, Z.; Chen, S.; Chang, Y., Investigation of the hydration of nonfouling material poly(sulfobetaine methacrylate) by low-field nuclear magnetic resonance. Langmuir 2012, 28 (19), 7436-7441.

24. Wu, J.; Chen, S., Investigation of the hydration of nonfouling material poly(ethylene glycol) by low-field nuclear magnetic resonance. Langmuir 2012, 28 (4), 2137-2144.

25. Sun, D.; Li, P.; Li, X.; Wang, X., Protein-resistant surface based on zwitterion-functionalized nanoparticles for marine antifouling applications. New Journal of Chemistry 2020, 44 (5), 2059-2069.

26. Liu, H.; Ma, Z.; Yang, W.; Pei, X.; Zhou, F., Facile preparation of structured zwitterionic polymer substrate via sub-surface initiated atom transfer radical polymerization and its synergistic marine antifouling investigation. European Polymer Journal 2019, 112, 146-152.

27. Xie, Q.; Xie, Q.; Pan, J.; Ma, C.; Zhang, G., Biodegradable polymer with hydrolysis-induced zwitterions for antibiofouling. ACS applied materials \& interfaces 2018, 10 (13), 11213-11220.

28. Claisse, D.; Alzieu, C., Copper contamination as a result of antifouling paint regulations? Marine Pollution Bulletin 1993, 26 (7), 395-397.

29. Turner, A., Marine pollution from antifouling paint particles. Marine Pollution Bulletin 2010, 60 (2), 159 171.

30. Perez, M.; Blustein, G.; Garcia, M.; del Amo, B.; Stupak, M., Cupric tannate: A low copper content antifouling pigment. Progress in Organic Coatings 2006, 55 (4), 311-315.

31. Cai, L.; Liu, A.; Yuan, Y.; Dai, L.; Li, Z., Self-assembled perfluoroalkylsilane films on silicon substrates for hydrophobic coatings. Progress in Organic Coatings 2017, 102, 247-258.

32. Pollack, K. A.; Imbesi, P. M.; Raymond, J. E.; Wooley, K. L., Hyperbranched fluoropolymerpolydimethylsiloxane-poly(ethylene glycol) cross-linked terpolymer networks designed for marine and biomedical Applications: heterogeneous nontoxic antibiofouling surfaces. ACS Applied Materials \& Interfaces 2014, 6 (21), 19265-19274.

33. Noguer, A. C., Experimental investigation of the behaviour and fate of block copolymers in foulingrelease coatings. Technical University of Denmark (DTU): Kgs. Lyngb, Denmark, 2016.

34. Murthy, R.; Bailey, B. M.; Valentin-Rodriguez, C.; Ivanisevic, A.; Grunlan, M. A., Amphiphilic silicones prepared from branched PEO-silanes with siloxane tethers. Journal of Polymer Science Part A: Polymer Chemistry 2010, 48 (18), 4108-4119.

35. Martinelli, E.; Suffredini, M.; Galli, G.; Glisenti, A.; Pettitt, M. E.; Callow, M. E.; Callow, J. A.; Williams, D.; Lyall, G., Amphiphilic block copolymer/poly (dimethylsiloxane)(PDMS) blends and nanocomposites for improved fouling-release. Biofouling 2011, 27 (5), 529-541.

36. Røn, T.; Javakhishvili, I.; Hvilsted, S.; Jankova, K.; Lee, S., Ultralow friction with hydrophilic polymer brushes in water as segregated from silicone matrix. Advanced Materials Interfaces 2016, 3 (2), 1500472. 
37. Rufin, M. A.; Barry, M. E.; Adair, P. A.; Hawkins, M. L.; Raymond, J. E.; Grunlan, M. A., Protein resistance efficacy of PEO-silane amphiphiles: Dependence on PEO-segment length and concentration. Acta Biomaterialia 2016, 41, 247-252.

38. Shivapooja, P.; Yu, Q.; Orihuela, B.; Mays, R.; Rittschof, D.; Genzer, J.; López, G. P., Modification of Silicone Elastomer Surfaces with Zwitterionic Polymers: Short-Term Fouling Resistance and Triggered Biofouling Release. ACS Applied Materials \& Interfaces 2015, 7 (46), 25586-25591.

39. Liu, Y.; Leng, C.; Chisholm, B.; Stafslien, S.; Majumdar, P.; Chen, Z., Surface Structures of PDMS Incorporated with Quaternary Ammonium Salts Designed for Antibiofouling and Fouling Release Applications. Langmuir 2013, 29 (9), 2897-2905.

40. Wan, F.; Pei, X.; Yu, B.; Ye, Q.; Zhou, F.; Xue, Q., Grafting Polymer Brushes on Biomimetic Structural Surfaces for Anti-Algae Fouling and Foul Release. ACS Applied Materials \& Interfaces 2012, 4 (9), 4557-4565.

41. Yeh, S.-B.; Chen, C.-S.; Chen, W.-Y.; Huang, C.-J., Modification of silicone elastomer with zwitterionic silane for durable antifouling properties. Langmuir 2014, 30 (38), 11386-11393.

42. Zhang, L.; Sha, J.; Chen, R.; Liu, Q.; Liu, J.; Yu, J.; Zhang, H.; Lin, C.; Wang, J., Three-dimensional flower-like shaped Bi5O7I particles incorporation zwitterionic fluorinated polymers with synergistic hydrationphotocatalytic for enhanced marine antifouling performance. Journal of Hazardous Materials 2020, 389, 121854. 43. Ciriminna, R.; Bright, F. V.; Pagliaro, M., Ecofriendly Antifouling Marine Coatings. ACS Sustainable Chemistry \& Engineering 2015, 3 (4), 559-565.

44. Galhenage, T. P.; Hoffman, D.; Silbert, S. D.; Stafslien, S. J.; Daniels, J.; Miljkovic, T.; Finlay, J. A.; Franco, S. C.; Clare, A. S.; Nedved, B. T., Fouling-release performance of silicone oil-modified siloxanepolyurethane coatings. ACS Applied Materials \& Interfaces 2016, 8 (42), 29025-29036.

45. Wei, C.; Zhang, G.; Zhang, Q.; Zhan, X.; Chen, F., Silicone Oil-Infused Slippery Surfaces Based on Sol-Gel Process-Induced Nanocomposite Coatings: A Facile Approach to Highly Stable Bioinspired Surface for Biofouling Resistance. ACS Applied Materials \& Interfaces 2016, 8 (50), 34810-34819.

46. Kavanagh, C. J.; Swain, G. W.; Kovach, B. S.; Stein, J.; Darkangelo-Wood, C.; Truby, K.; Holm, E.; Montemarano, J.; Meyer, A.; Wiebe, D., The Effects of Silicone Fluid Additives and Silicone Elastomer Matrices on Barnacle Adhesion Strength. Biofouling 2003, 19 (6), 381-390.

47. Selim, M. S.; El-Safty, S. A.; Azzam, A. M.; Shenashen, M. A.; El-Sockary, M. A.; Abo Elenien, O. M., Superhydrophobic silicone/TiO2-SiO2 nanorod-like composites for marine fouling release coatings. ChemistrySelect 2019, 4 (12), 3395-3407.

48. Beigbeder, A.; Mincheva, R.; Pettitt, M. E.; Callow, M. E.; Callow, J. A.; Claes, M.; Dubois, P., Marine fouling release silicone/carbon nanotube nanocomposite coatings: on the importance of the nanotube dispersion state. Journal of Nanoscience and Nanotechnology 2010, 10 (5), 2972-2978.

49. Beigbeder, A.; Labruyère, C.; Viville, P.; Pettitt, M. E.; Callow, M. E.; Callow, J. A.; Bonnaud, L.; Lazzaroni, R.; Dubois, P., Surface and fouling-release properties of silicone/organomodified montmorillonite coatings. Journal of Adhesion Science and Technology 2011, 25 (14), 1689-1700. 
50. Selim, M. S.; El-Safty, S. A.; El-Sockary, M. A.; Hashem, A. I.; Elenien, O. M. A.; El-Saeed, A. M.; Fatthallah, N. A., Smart photo-induced silicone/TiO2 nanocomposites with dominant [110] exposed surfaces for self-cleaning foul-release coatings of ship hulls. Materials \& Design 2016, 101, 218-225.

51. Arukalam, I. O.; Oguzie, E. E.; Li, Y., Fabrication of FDTS-modified PDMS-ZnO nanocomposite hydrophobic coating with anti-fouling capability for corrosion protection of Q235 steel. Journal of Colloid and Interface Science 2016, 484, 220-228.

52. Stafslien, S.; Daniels, J.; Mayo, B.; Christianson, D.; Chisholm, B.; Ekin, A.; Webster, D.; Swain, G., Combinatorial materials research applied to the development of new surface coatings IV. A high-throughput bacterial biofilm retention and retraction assay for screening fouling-release performance of coatings. Biofouling 2007, 23 (1), 45-54.

53. Liaw, D.-J.; Lee, W.-F., Thermal degradation of poly[3-dimethyl(methylmethacryloylethyl) ammonium propanesulfonate]. Journal of Applied Polymer Science 1985, 30 (12), 4697-4706.

54. Bodkhe, R. B.; Webster, D. C., Synthesis and characterization of novel polysiloxane based aba-type triblock copolymers using atrp. e-Polymers 2013, 13 (1).

55. Jakubowski, K.; Min, K.; Matyjaszewski, K., Activators regenerated by electron transfer for atom transfer radical polymerization of styrene. Macromolecules 2006, 39 (1), 39-45.

56. Min, K.; Gao, H.; Matyjaszewski, K., Use of ascorbic acid as reducing agent for synthesis of welldefined polymers by ARGET ATRP. Macromolecules 2007, 40 (6), 1789-1791.

57. Owens, D. K.; Wendt, R. C., Estimation of the surface free energy of polymers. Journal of Applied Polymer Science 1969, 13 (8), 1741-1747.

58. Casse, F.; Ribeiro, E.; Ekin, A.; Webster, D. C.; Callow, J. A.; Callow, M. E., Laboratory screening of coating libraries for algal adhesion. Biofouling 2007, 23 (4), 267-276.

59. Stafslien, S. J.; Bahr, J. A.; Daniels, J. W.; Wal, L. V.; Nevins, J.; Smith, J.; Schiele, K.; Chisholm, B., Combinatorial materials research applied to the development of new surface coatings VI: An automated spinning water jet apparatus for the high-throughput characterization of fouling-release marine coatings. Review of Scientific Instruments 2007, 78 (7), 072204-072204.

60. Cassé, F.; Stafslien, S. J.; Bahr, J. A.; Daniels, J.; Finlay, J. A.; Callow, J. A.; Callow, M. E., Combinatorial materials research applied to the development of new surface coatings $\mathrm{V}$. Application of a spinning water-jet for the semi-high throughput assessment of the attachment strength of marine fouling algae.

Biofouling 2007, 23 (2), 121-130.

61. Stafslien, S.; Daniels, J.; Bahr, J.; Chisholm, B.; Ekin, A.; Webster, D.; Orihuela, B.; Rittschof, D., An improved laboratory reattachment method for the rapid assessment of adult barnacle adhesion strength to fouling-release marine coatings. Journal of Coatings Technology and Research 2012, 9 (6), 651-665.

62. Rittschof, D.; Orihuela, B.; Stafslien, S.; Daniels, J.; Christianson, D.; Chisholm, B.; Holm, E., Barnacle reattachment: a tool for studying barnacle adhesion. Biofouling 2008, 24 (1), 1-9.

63. Utex, S. R. Z. J. A., The Culture Collection of Algae at the University of Texas at Austin. J. Phycol. 1987 मf $23,1-47$. 
64. Kitano, H.; Mori, T.; Takeuchi, Y.; Tada, S.; Gemmei-Ide, M.; Yokoyama, Y.; Tanaka, M., Structure of water incorporated in sulfobetaine polymer films as studied by ATR-FTIR. Macromolecular Bioscience 2005, 5 (4), 314-321.

65. Shultz, A. R.; Flory, P. J., Phase equilibria in polymer-solvent systems1,2. Journal of the American Chemical Society 1952, 74 (19), 4760-4767.

66. Stafslien, S. J.; Bahr, J. A.; Feser, J. M.; Weisz, J. C.; Chisholm, B. J.; Ready, T. E.; Boudjouk, P., Combinatorial Materials Research Applied to the Development of New Surface Coatings I: A Multiwell Plate Screening Method for the High-Throughput Assessment of Bacterial Biofilm Retention on Surfaces. Journal of Combinatorial Chemistry 2006, 8 (2), 156-162.

67. Finlay, J. A.; Callow, M. E.; Ista, L. K.; Lopez, G. P.; Callow, J. A., The influence of surface wettability on the adhesion strength of settled spores of the green alga Enteromorpha and the diatom Amphora. Integrative and Comparative Biology 2002, 42 (6), 1116-1122.

68. Callow, J. A.; Callow, M. E.; Ista, L. K.; Lopez, G.; Chaudhury, M. K., The influence of surface energy on the wetting behaviour of the spore adhesive of the marine alga Ulva linza (synonym Enteromorpha linza). Journal of the Royal Society Interface 2005, 2 (4), 319-325.

69. Callow, M. E.; Callow, J. A.; Ista, L. K.; Coleman, S. E.; Nolasco, A. C.; López, G. P., Use of selfassembled monolayers of different wettabilities to study surface selection and primary adhesion processes of green algal (Enteromorpha) zoospores. Applied Environmental Microbiology 2000, 66 (8), 3249-3254.

70. Holland, R.; Dugdale, T. M.; Wetherbee, R.; Brennan, A. B.; Finlay, J. A.; Callow, J. A.; Callow, M. E., Adhesion and motility of fouling diatoms on a silicone elastomer. Biofouling 2004, 20 (6), 323-329.

71. Aldred, N.; Li, G.; Gao, Y.; Clare, A. S.; Jiang, S., Modulation of barnacle (Balanus amphitrite Darwin) cyprid settlement behavior by sulfobetaine and carboxybetaine methacrylate polymer coatings. Biofouling 2010, $26(6), 673-683$.

72. Petrone, L.; Di Fino, A.; Aldred, N.; Sukkaew, P.; Ederth, T.; Clare, A. S.; Liedberg, B., Effects of surface charge and Gibbs surface energy on the settlement behaviour of barnacle cyprids (Balanus amphitrite). Biofouling 2011, 27 (9), 1043-1055.

73. Di Fino, A.; Petrone, L.; Aldred, N.; Ederth, T.; Liedberg, B.; Clare, A. S., Correlation between surface chemistry and settlement behaviour in barnacle cyprids (Balanus improvisus). Biofouling 2014, 30 (2), 143-152.

74. Gatley-Montross, C. M.; Finlay, J. A.; Aldred, N.; Cassady, H.; Destino, J. F.; Orihuela, B.; Hickner, M. A.; Clare, A. S.; Rittschof, D.; Holm, E. R., Multivariate analysis of attachment of biofouling organisms in response to material surface characteristics. Biointerphases 2017, 12 (5), 051003.

75. Aldred, N.; Gatley-Montross, C. M.; Lang, M.; Detty, M. R.; Clare, A. S., Correlative assays of barnacle cyprid behaviour for the laboratory evaluation of antifouling coatings: a study of surface energy components.

Biofouling 2019, 35 (2), 159-172.

76. Huggett, M. J.; Nedved, B. T.; Hadfield, M. G., Effects of initial surface wettability on biofilm formation and subsequent settlement of Hydroides elegans. Biofouling 2009, 25 (5), 387-399.

77. Rittschof, D.; Costlow, J. D., Bryozoan and barnacle settlement in relation to initial surface wettability: A comparison of laboratory and field studies. Sci. Mar. 1989, 53 (2), 411-416. 
